\title{
Putting Climate Adaptation on the Map: Developing Spatial Management Strategies for Whitebark Pine in the Greater Yellowstone Ecosystem
}

\section{Authors: Kathryn B. Ireland, Andrew J. Hansen, Robert E. Keane, Kristin Legg, and Robert L. Gump}

The final publication is available at Springer via http://dx.doi.org/10.1007/s00267-018-1029-2

Ireland, Kathryn B. , Andrew J. Hansen, Robert E. Keane, Kristin Legg, and Robert L. Gump. "Putting Climate Adaptation on the Map: Developing Spatial Management Strategies for Whitebark Pine in the Greater Yellowstone Ecosystem." Environmental Management 61, no. 6 (June 2018): 981-1001. DOI:10.1007/s00267-018-1029-2. 


\title{
Putting Climate Adaptation on the Map: Developing Spatial Management Strategies for Whitebark Pine in the Greater Yellowstone Ecosystem
}

\author{
Kathryn B. Ireland $\mathbb{1}^{1,5} \cdot$ Andrew J. Hansen ${ }^{1} \cdot$ Robert E. Keane ${ }^{2} \cdot$ Kristin Legg $^{3} \cdot$ Robert L. Gump ${ }^{4}$
}

\begin{abstract}
Natural resource managers face the need to develop strategies to adapt to projected future climates. Few existing climate adaptation frameworks prescribe where to place management actions to be most effective under anticipated future climate conditions. We developed an approach to spatially allocate climate adaptation actions and applied the method to whitebark pine (WBP; Pinus albicaulis) in the Greater Yellowstone Ecosystem (GYE). WBP is expected to be vulnerable to climatemediated shifts in suitable habitat, pests, pathogens, and fire. We spatially prioritized management actions aimed at mitigating climate impacts to WBP under two management strategies: (1) current management and (2) climate-informed management. The current strategy reflected management actions permissible under existing policy and access constraints. Our goal was to understand how consideration of climate might alter the placement of management actions, so the climateinformed strategies did not include these constraints. The spatial distribution of actions differed among the current and climate-informed management strategies, with 33-60\% more wilderness area prioritized for action under climate-informed management. High priority areas for implementing management actions include the 1-8\% of the GYE where current and climate-informed management agreed, since this is where actions are most likely to be successful in the long-term and where current management permits implementation. Areas where climate-informed strategies agreed with one another but not with current management (6-22\% of the GYE) are potential locations for experimental testing of management actions. Our method for spatial climate adaptation planning is applicable to any species for which information regarding climate vulnerability and climate-mediated risk factors is available.
\end{abstract}

Keywords Climate adaptation $\cdot$ Spatially explicit $\cdot$ Management $\cdot$ Whitebark pine $\cdot$ Greater Yellowstone

Electronic supplementary material The online version of this article (https://doi.org/10.1007/s00267-018-1029-2) contains supplementary material, which is available to authorized users.

Kathryn B. Ireland

kathryn.ireland@wwfus.org

1 Department of Ecology, Montana State University, P. O. Box 173460, Bozeman, MT 59717-3460, USA

2 USDA Forest Service Rocky Mountain Research Station, Missoula Fire Sciences Laboratory, 5775 U.S. Highway 10, Missoula, MT 59808, USA

3 Inventory and Monitoring Division, Greater Yellowstone Network, National Park Service, 2327 University Way Suite 2, Bozeman, MT 59715, USA

4 USDA Forest Service Bitterroot National Forest, 1801 N. First street, Hamilton, MT 59840, USA

5 Present address: World Wildlife Fund, Northern Great Plains Program, 13 South Willson Avenue, Suite 1, Bozeman, MT, USA

\section{Introduction}

Impacts of climate change on forest ecosystems are increasingly evident. Warming temperatures and decreased moisture availability have been linked to widespread forest die-off from both drought stress (Allen et al. 2010) and extensive bark beetle outbreaks (Bentz et al. 2010). The frequency and extent of wildfires have increased as warmer spring temperatures have lengthened fire seasons (Westerling et al. 2006). The direct effects of climate change combined with indirect effects through modification of disturbance regimes may lead to the decline or loss of vulnerable species (Bell et al. 2013; Coops and Waring 2011; Hansen and Phillips 2015; McKinney et al. 2011; Thuiller et al. 2005). Under the current emissions trajectory, many climate models project an increase of $1.4-4.8^{\circ} \mathrm{C}$ in 
mean global annual surface temperatures by 2100 (IPCC 2014), so these impacts are likely to continue.

As information on the impacts of climate change to forest ecosystems has increased, so has recognition that natural resource managers need to incorporate climate change into their management planning and decisions (Archie et al. 2012; Lemieux et al. 2013; Mimura et al. 2014; West et al. 2009). Initial climate adaptation planning efforts focused on broad conceptual issues such as how much to resist or embrace change (Millar et al. 2007) or outlined general steps such as assessing vulnerability (Glick et al. 2011b). Although initial climate adaptation recommendations often lacked the specificity required for action (Heller and Zavaleta 2009), adaptation planning efforts are increasingly providing more specific recommendations (Glick et al. 2011a). In recent years, detailed methods have been developed to assist natural resource managers in translating broad climate change adaptation concepts to management actions through the use of frameworks (Cross et al. 2012b; Stein et al. 2014), guidebooks (Peterson et al. 2011; Swanston and Janowiak 2012), scenario-planning (National Park Service 2013; Peterson et al. 2003), sciencemanagement partnerships (Halofsky and Peterson 2016; Littell et al. 2011), and decision-support tools (Morelli et al. 2012; Nelson et al. 2016; Ogden and Innes 2009).

Despite the proliferation of tools to assist with climate adaptation decision making, on-the-ground implementation of these adaptation efforts remains rare (Bierbaum et al. 2013; Hansen et al. 2013; Kemp et al. 2015). The vast majority of climate adaptation activity in natural resource management to date has been focused on climate impacts and vulnerability assessments with a recent increase in effort towards development of resources, tools, and associated planning. Yet, few climate adaptation plans have been implemented (Bierbaum et al. 2013; Hansen et al. 2013). Where implementation has occurred, it has often been localized and in response to extreme weather events such as floods, fire, or storms (Bierbaum et al. 2013; Hansen et al. 2013; Mimura et al. 2014).

Several barriers prevent climate adaptation plans from moving toward implementation. In a survey of natural resource managers, the lack of adaptation actions defined at management-relevant scales was one of the most frequently identified barriers to implementation (Lemieux et al. 2013). Additionally, managers often feel that adaptation plans are not specific enough to be actionable at local scales (lack critical detail for implementation, e.g., lack a prescription for thinning) (Olliff et al. 2016). The great uncertainty about the magnitude and impacts of climate change as well as the likely ability of management actions to mitigate those effects is frequently a barrier to implementation of adaptation actions (Lawler et al. 2010; Willows and Connell 2003). Recommendations for how to address this uncertainty in climate adaptation planning include scenario planning (planning for multiple potential future climate conditions), focusing on "no-regret" management decisions (those likely to have multiple benefits under several scenarios and with little risk of undesirable outcomes), and adaptively learning from experimentation (Cross et al. 2012b; Lawler et al. 2010; Millar et al. 2007, 2014; Peterson et al. 2003; Willows and Connell 2003).

One barrier to the implementation of climate adaptation lies is determining where to distribute management actions across the landscape to be most effective under future conditions. Very few studies have tackled this challenge, but those which have often use projections of future climate suitability for a given species as a filter for spatially prioritizing management goals and actions. For example, Hennon et al. (2012) identified and proposed different management priorities for yellow-cedar (Calliptropsis nootkanensis) in southeast Alaska based on suitability of climate and soils under changing climate conditions in maladapted (declining suitability), persistent (suitable now and in future), and migration zones (suitable in future). In the maladapted zone, management recommendations would be to facilitate conversion to other species and potential conservation on limited suitable habitats. Silvicultural actions aimed at maintaining yellow-cedar (i.e., planting seedlings, thinning competing species) would be prioritized in the persistent zone, while assisted or facilitated migration might be considered in the migration zone (Hennon et al. 2012). Similarly, Cole et al. (2011), modeled the climatic niche of Joshua tree (Yucca brevifolia), classified areas of sustainable and unsustainable future habitat, and identified areas with the potential for natural versus assisted migration based on rates of Joshua tree migration from paleoecological studies. Based on overlays of current and future suitable habitat for different genetic populations of two European conifer species, Serra-Varela et al. (2017) made recommendations of where in situ or ex situ (i.e, seed banks, translocations) management should be most effective for managing distinct genetic populations.

We seek to contribute to the burgeoning field of climate adaptation planning by presenting a method to prioritize where on the landscape management actions might be effective under future climate conditions. Most climate adaptation frameworks involve cycling through identifying the target or goal, assessing climate change impacts, identifying appropriate management actions, prioritizing management actions, implementing management actions, and evaluating and monitoring management actions (Fig. 1; e.g., Cross et al. 2012b; Stein et al. 2014). We extend this approach by spatially prioritizing management actions across the landscape to account for how rates of climate change, species response to this change, management feasibility, and management effectiveness are expected to vary 
Fig. 1 The steps used to develop spatially explicit climate adaptation plans and inputs used. We applied these steps to whitebark pine in the Greater Yellowstone Ecosystem, but the steps used here were designed to be applicable to other species and geographic locations. The general steps are shown in the unshaded squares; outputs from each step and associated tables or figures within the paper are listed in parentheses. The inputs and techniques we used for whitebark pine and associated tables and figures in this paper are shown in the shaded ellipses

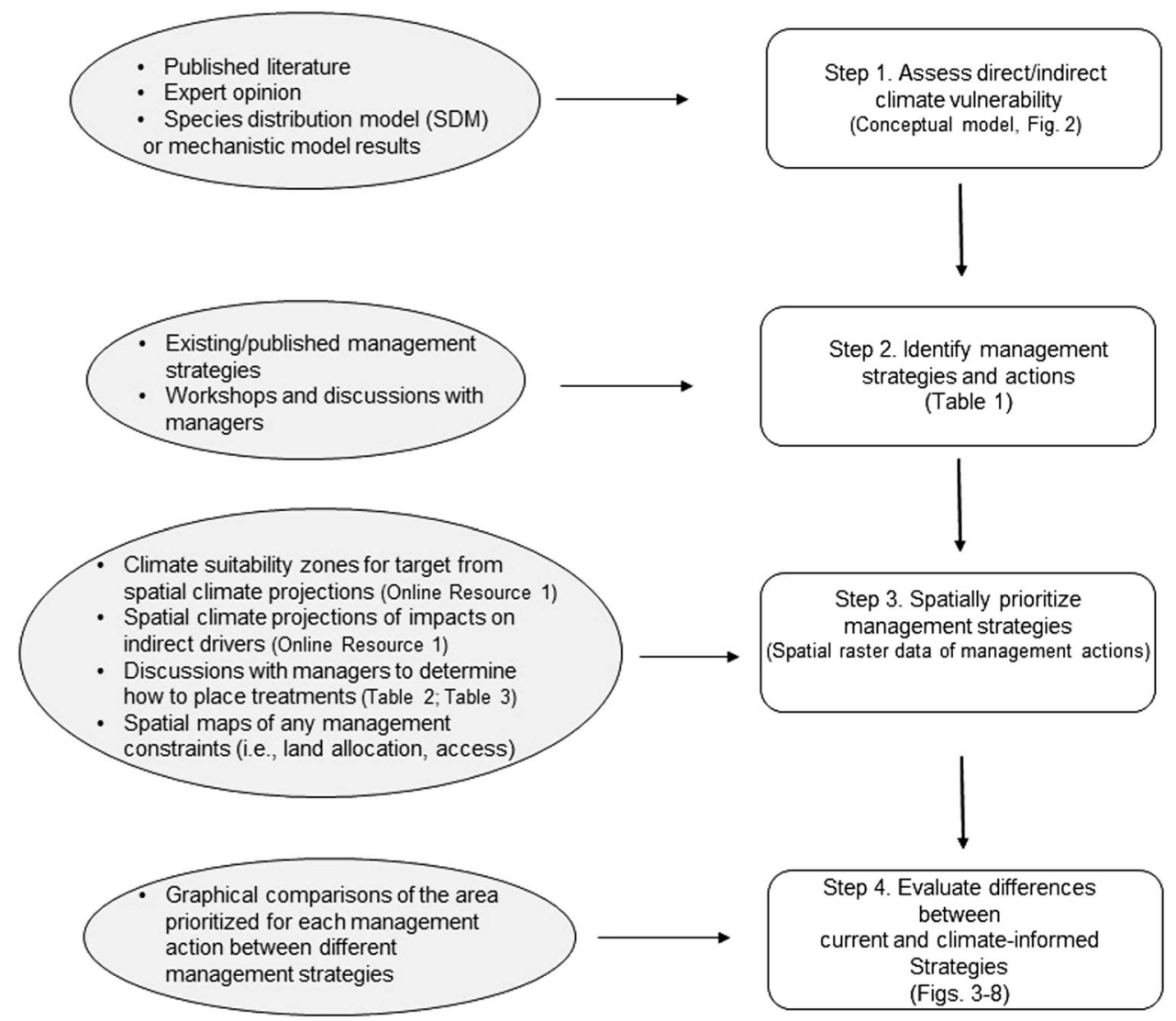

with topography, soils, land class, and distance from infrastructure.

In this paper, we illustrate four steps involved in developing a spatial climate adaptation plan (Fig. 1) using whitebark pine (WBP; Pinus albicaulis) in the Greater Yellowstone Ecosystem (GYE) as an example management target. We selected WBP because, like the examples of yellow-cedar and Joshua tree, it is expected to rapidly respond to climate impacts. Amongst conifer species in the Northern Rockies, WBP is projected to be the most vulnerable to climate change (Hansen and Phillips 2015). The U.S. Fish and Wildlife Service has listed WBP on its U.S. Candidate species list under the Endangered Species Act in response to current threats from mountain pine beetles, fire exclusion management policies, and the introduced disease white pine blister-rust (U.S. Fish and Wildlife Service 2011), all of which could be exacerbated by climate change (Hansen et al. 2016). Such early responding species are excellent candidates for exploring methods of developing climate adaptation strategies.

First, we assessed the likely climate impacts, both direct and indirect, on WBP with emphasis on how these vary spatially. This step began with developing a conceptual model describing the various drivers of WBP's population dynamics and how each of these drivers might be influenced by changing climate conditions. Then, we reviewed current management strategies for WBP and worked closely with managers in the GYE working on WBP management to identify potential management actions. In the third step, we developed a spatial prioritization of the identified management actions by incorporating spatial projections of the direct impacts of climate and one indirect driver, competition, on WBP under multiple climate scenarios. Finally, we compared current management practices with our more climate-informed strategies. Current management practices for WBP in GYE prioritize management actions where they will be most efficacious based on ecological criteria, while considering existing financial, access, and legal or policy constraints based on land class. For example, active management actions such as thinning or planting blister-rustresistant WBP seedlings are not currently permitted in Wilderness lands or feasible in remote locations far from roads and trails. However, it is currently unknown how effective current management practices will be as climate changes. As a first step in evaluating how the spatial distribution of treatments might need to be altered to account for future climate, we developed a climate-informed management strategy aimed at maximizing preservation of whitebark in the GYE under future climate conditions. Because our goal was to understand how consideration of 
climate might alter the placement of management actions, the climate-informed strategies did not include the legal, policy, and access constraints under which management currently operates. Thus, our climate-informed strategies represent the most extreme changes that might need to be considered to maintain WBP under future climate conditions. By comparing the current and climate-informed strategies, we hoped to assist managers in the GYE with incorporating climate science into their current management. More generally, our approach should be useful for application to other species and geographic locations.

\section{Study Area}

The GYE encompasses an area of $150,700 \mathrm{~km}^{2}$, crossing portions of Montana, Idaho and Wyoming (Schrag et al. 2008). The GYE includes two national parks (Yellowstone and Grand Teton) and portions of five national forests, Bureau of Land Management, and US Fish and Wildlife lands, as well as state, private, and tribal lands. Elevations range from $522-4206 \mathrm{~m}$. Temperatures in the region have been increasing since 1948, with the most pronounced warming in the winter and summer months (Sepulveda et al. 2015). Warming winter temperatures have led to reduced snow accumulation and earlier snowmelt (Sepulveda et al. 2015).

The GYE is a northern temperate region, with forests dominated by conifer species (Despain 1990; Marston and Anderson 1991). Vegetation patterns are linked to elevation and precipitation gradients (Despain 1990; Marston and Anderson 1991). Arid lowlands are dominated by sagebrush (Artemisia spp.) shrublands and open grasslands (Marston and Anderson 1991). As moisture increases with elevation, woodlands of Rocky Mountain juniper (Juniperus scopulorum) and limber pine (Pinus flexilis) transition to Douglas-fir (Pseudotsuga menziessii) forests (Marston and Anderson 1991). At higher elevations dominated by rhyolitic soils, lodgepole pine (Pinus contorta) forests dominate (Despain 1990; Marston and Anderson 1991). Quaking aspen is also widespread, although generally in small patches (Marston and Anderson 1991). Cottonwood species (Populus angustifolia, P. balsamifera, and P. trichocarpa) and willows (Salix spp.) dominate riparian communities (Marston and Anderson 1991). Subalpine forests are comprised of subalpine fir (Abies lasiocarpa), Engelmann spruce (Picea engelmannii), and WBP (Despain 1990; Marston and Anderson 1991). Stunted stands of WBP, Engelmann spruce, and WBP form the upper treeline (Marston and Anderson 1991). The GYE represents 53\% of WBP's distribution in the United States (Hansen et al. 2016), making the region an important place to develop spatial climate adaptation plans for the species.

\section{Step 1. Assess Direct and Indirect Climate Vulnerability}

Our first step was to assess the direct and indirect effects that climate change could be expected to have on WBP in the GYE based on previous studies. Climate change is expected to bring warmer temperatures and increased aridity to the GYE in the coming century (Chang 2015). Mean annual temperatures are expected to increase by $3.3-7.2^{\circ} \mathrm{C}$ by 2100 (Chang 2015), with the most pronounced changes in winter and summer (Sepulveda et al. 2015). Predictions of mean annual precipitation vary from an $8 \%(5 \mathrm{~cm})$ decrease to a $35 \%(23 \mathrm{~cm})$ increase (Chang 2015). Precipitation is projected to rise most rapidly in spring and decrease in summer (Chang 2015). Changes in precipitation are not projected to increase enough to offset the effects of rising temperatures, leading to increases in aridity (Chang 2015). Snowpack is expected to decline and snowmelt to occur earlier (Chang 2015; Sepulveda et al. 2015) Changes to spring precipitation and earlier snowmelt are projected to lead to increases in mean annual runoff (Chang and Hansen 2015).

We built a conceptual model describing how climate change may directly and indirectly affect WBP populations (Fig. 2). Climate change may directly influence WBP populations through its effects on survival, establishment, dispersal, growth, and reproduction (Hansen et al. 2016). Warming temperatures could have either a positive or negative affect on WBP populations, but increased drought would likely negatively impact WBP populations (Fig. 2). The upper elevational limit of WBP is thought to be constrained by cool growing season temperatures and drought (Weaver 1994). Although WBP is physiologically capable of growing in areas with warmer temperatures than where it currently occurs (Hansen et al. 2016; Jacobs and Weaver 1990), the physiological limit at lower elevations is thought to be related to drought (Weaver 1994) and competition (Arno and Hoff 1989). Thus, increased temperatures could allow WBP to expand upward into alpine habitats if other factors (i.e., developed soils, desiccating winds) were not limiting. However, at the lower elevational limit, increasing aridity, and competition from other conifers could limit WBP's physiological ability to move downslope. As climate changes, reduced snowpack and longer growing seasons could enhance regeneration by allowing seedlings more time to grow (Keane et al. 2017). Longer growing seasons may also increase productivity of established WBP trees where precipitation remains sufficient (Keane et al. 2017). Alternatively, earlier snowmelt and longer growing seasons could reduce summer soil moisture, increasing drought stress, and reducing WBP growth (van de Gevel et al. 2017). Overall, climate change is projected to decrease the area of future suitable habitat for WBP across its range 
Fig. 2 Conceptual model describing the projected direct and indirect effects of future climate conditions on WBP. Positive and negative signs indicate the nature of the effect (adapted from Hansen et al. 2016)

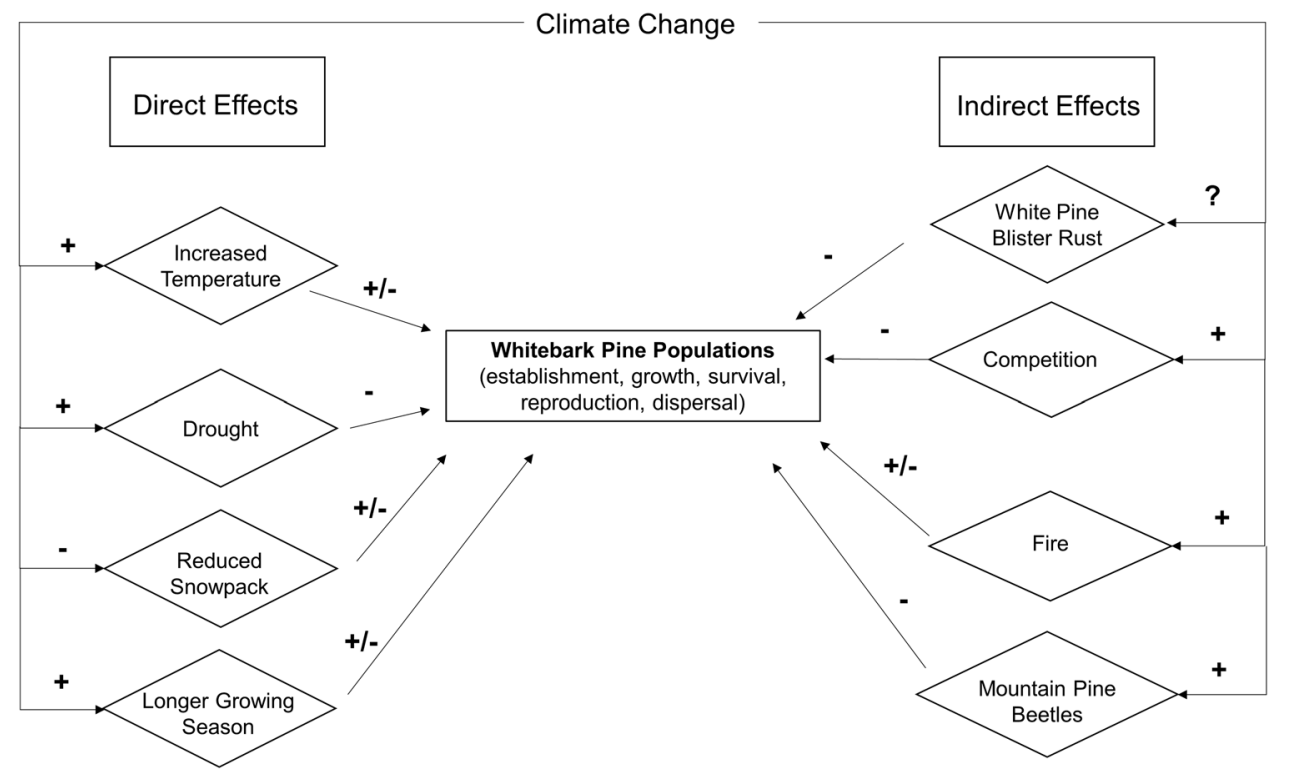

(Coops and Waring 2011; Crookston et al. 2010; Warwell et al. 2007). In the GYE, the area of climatically suitable habitat for WBP is projected to decrease by $82-95 \%$ by 2100 , depending on the climate scenario used (Chang et al. 2014).

Indirectly, climate change also influences WBP through its effects on biotic interactions, disturbance, and associated changes to demographic processes (Hansen et al. 2016). WBP populations have been declining throughout their range as a result of recent mountain pine beetle (Dendroctonus ponderosae) outbreaks, spread of the invasive white pine blister-rust disease (caused by Cronartium ribicola), and fire exclusion policies that heighten competition with other shade tolerant conifer tree species (Keane et al. 2012), all of which are influenced by changing climate conditions (Fig. 2). If warming temperatures favor other tree species, then competition could reduce WBP growth and establishment (Fig. 2). Future suitable habitat for subalpine fir, Engelmann spruce, Douglas-fir, and lodgepole pine, the tree species which most commonly co-occur with WBP in the GYE, is projected to improve in areas currently suitable for WBP, potentially reducing WBP growth and establishment (Hansen et al. 2016; Piekielek et al. 2015). Under future climate conditions, WBP mortality is predicted to increase as future winter and fall temperatures promote increased mountain pine beetle survival (Buotte et al. 2016). White pine blister-rust infection rates in the GYE have historically been lower than in other portions of WBP's distribution (20-30\%; Shanahan et al. 2014). Although cold, dry climate conditions were once thought to have slowed blister-rust infection in the GYE, the fungus is now present across nearly the entire distribution of WBP (Kliejunas et al. 2009; Geils et al. 2010). White pine blister-rust infection and mortality are expected to increase in the GYE in the next 20 years (Hatala et al. 2010). Although climate change is likely to increase fire frequency, size, and the length of the fire season (Westerling et al. 2006), the effects of these changes on WBP populations is less clear. An increase in frequency of mixed-severity fire could potentially favor WBP over its competitors and provide opportunities for regeneration, but an increase in frequency of high severity fires could potentially kill mature seed producing WBP trees (Keane et al. 2017). Further, if fires of any severity become too frequent, WBP trees may be prevented from growing to maturity as seedlings are unable to grow above lethal scorch heights (Keane et al. 2017).

\section{Step 2. Identify Management Strategies and Actions}

Once the potential impacts of climate change on WBP had been assessed, the next step was to identify the specific management actions that would likely be effective at mitigating climate impacts. To identify the management strategies and tactics to be used in our spatial climate adaptation plan we looked to previously published recommendations (Keane et al. 2017, 2012), existing management strategies (GYCC WBSC 2011), and partnerships with managers. Strong partnerships between scientists and managers are essential to successful climate adaptation planning, by allowing for communication between scientists and managers regarding the scientific basis for adaptation and 
bringing management expertise to the discussion to develop management options (Littell et al. 2011). Through workshops, meetings, and one-on-one conversations, we worked with federal land managers to adapt current WBP conservation strategies to incorporate projected climate change impacts.

The management strategies that have been identified to address current threats to WBP populations in the GYE can be adapted to address the challenges of climate change. A recent range-wide strategy (Keane et al. 2012) and subsequent incorporation of climate change into that strategy (Keane et al. 2017) identified four guiding principles of WBP restoration: promote rust resistance, conserve genetic diversity, save seed sources, and employ restoration actions. Specific management actions related to these guiding principles include planting blister-rust-resistant WBP seedlings, silvicultural thinning to reduce competition and increase tree vigor, and balancing the use of prescribed fire and wildland fire to promote landscape heterogeneity (to reduce future risk of high severity fires, maintain ecosystem function, promote age class diversity, and reduce vulnerability to mountain pine beetles) (Keane et al. 2016). In considering how to manage WBP in the face of climate change, the authors note that the biggest challenge to implementation of many of these management actions is deciding where to place management actions to be most effective in the longterm (Keane et al. 2017).

In addition to the more general range-wide restoration strategies, we also based our management actions on a WBP management strategy specific to the GYE. The Greater Yellowstone Coordinating Committee (GYCC), an interagency coalition of representatives from all federal agencies in the GYE, prepared a strategy aimed at protecting and restoring WBP across federally managed lands in the GYE (GYCC WBSC 2011). The GYCC WBP strategy outlined specific protection and restoration actions for managing WBP under current conditions (Table 1; GYCC WBSC 2011). The management actions identified by the GYCC can be broadly categorized as planting of blister-rust-resistant WBP seedlings, thinning (for competition removal, to promote regeneration, or to reduce mortality risk from mountain pine beetle), mountain pine beetle protection (using insecticides and pheromones to protect selected trees or stands), and fire use (either wildland fire use planning to protect cone-bearing WBP trees from fire mortality or prescribed fire) (Table 1). We based our climate-informed management strategies on the management actions identified in the range-wide restoration documents (Keane et al. 2017, 2012) and GYCC WBP strategy (GYCC WBSC 2011), but used projections of future climate impacts to prioritize where on the landscape each tactic should be implemented, as described below.

\section{Step 3. Spatially Prioritize Management Strategies}

We developed spatial management strategies for both current management and climate-informed management. In both strategies, the mapped management actions were the broad categories derived from the GYCC WBP Strategy document as discussed in the previous section: planting of blister-rust-resistant WBP seedlings, competition removal thinning, mountain pine beetle protection, and fire use (both wildland fire use planning and prescribed fire) (Table 1). A spatial representation of the current GYCC WBP Strategy reflected constraints based on access and land status. Active management actions (thinning, planting, mountain pine beetle protection) are currently allowed on most national forest lands, but these same actions are currently discouraged or prohibited in Wilderness areas (Hansen et al. 2016). Therefore, the current management strategy allowed active management in federal non-Wilderness lands, but restricted most actions in Wilderness lands. In contrast, the climate-informed strategy was based only on the anticipated direct and indirect effects of future climate conditions on WBP and did not include access, logistical, or jurisdictional constraints. Thus, an important distinction between the two strategies lies in whether active management actions were allowed in certain land classes. We allowed management actions in Wilderness lands in the climate-informed strategy because this strategy was designed to maximize the preservation of WBP forests. Since $68 \%$ of WBP's current distribution in the GYE lies within Wilderness (Hansen et al. 2016), this meant that the climate-informed strategy would permit management actions in certain locations within Wilderness areas where climate projections indicated management actions would be effective. This contrast allowed us to evaluate where changes to current management might need to be considered to effectively manage WBP forests in the future.

To develop the current management strategy, we relied on land classes to prioritize specific management actions only where those action would be possible under current access, logistical, and legal or jurisdictional limitations (Hansen et al. 2016). For example, the ability to plant blister-rust-resistant seedlings or remove competing conifer species is restricted in federally designated Wilderness areas and is often infeasible in areas distant from roads or trails. Based on discussions with members of the GYCC WBP subcommittee, we used differences in land classes and distance from roads and trails to map where different management activities would be feasible under the current management strategy (Table 2). Land classes were derived from a federal land ownership dataset (USGS 2006), which we reclassified into multiple use forest areas (non-Wilderness and inventoried roadless areas on U.S. Forest 


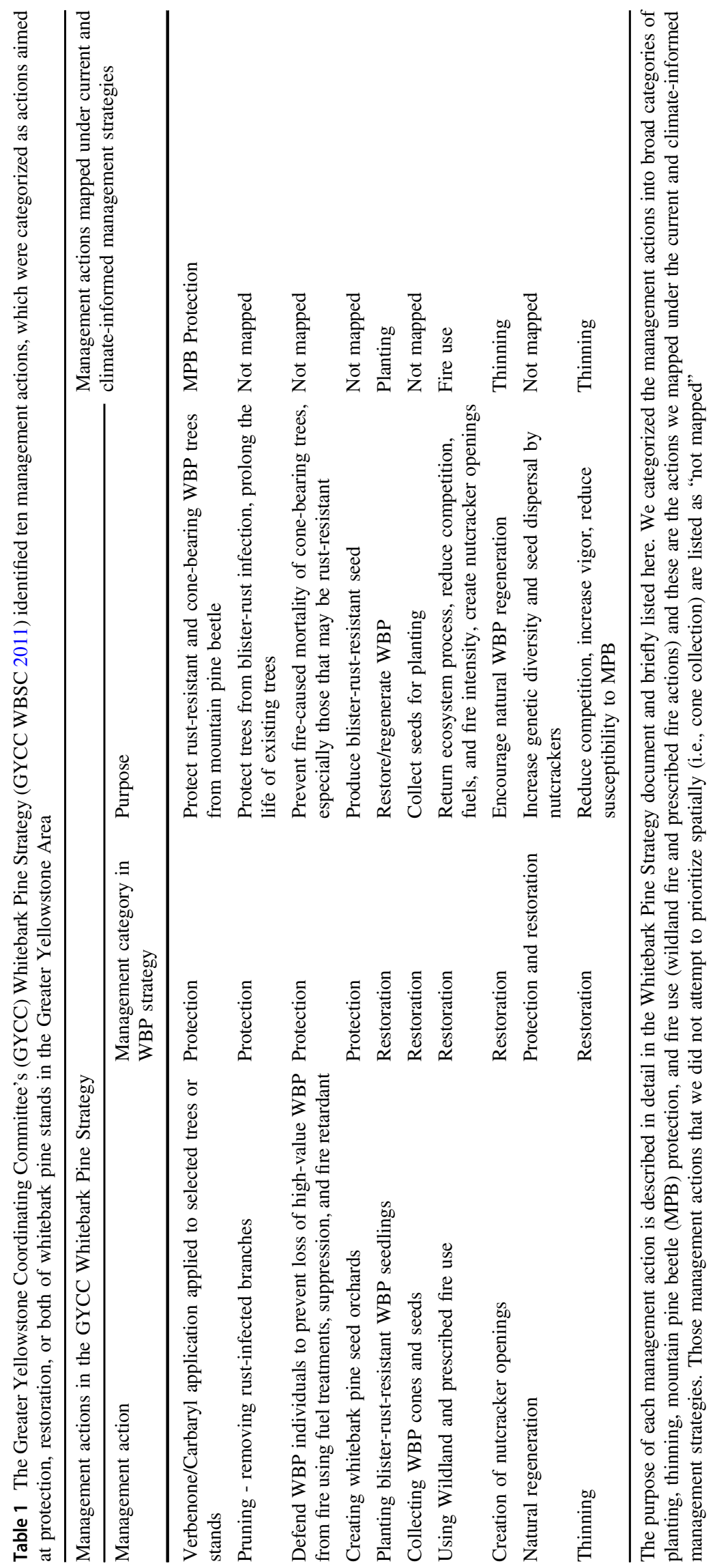




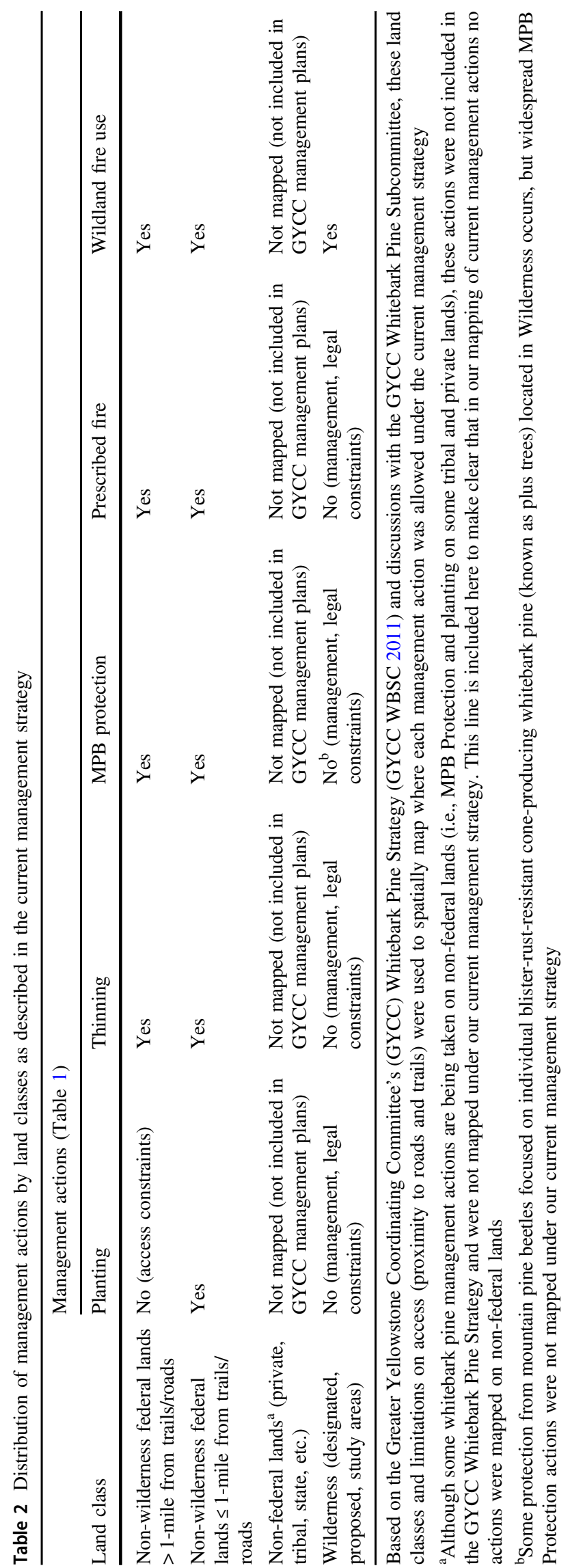

Service, Bureau of Land Management, Fish and Wildlife Service, or National Park Service lands), Wilderness areas (designated, proposed, and wilderness study areas), and non-federal lands (private, state, Native American lands). All management actions were mapped as available on nonwilderness federal lands within 1-mile of roads and trails (Table 2). Due to access constraints beyond $1.6 \mathrm{~km}$ (1-mile) from roads and trails, planting was excluded from locations farther than $1.6 \mathrm{~km}$ from roads and trails (Table 2). Only wildland fire use actions were mapped as available on Wilderness lands, due to current limitations on thinning, planting, and mountain pine beetle preventative actions (Table 2). Because the current WBP strategy developed by the GYCC WBP Subcommittee applies only to federal lands, no actions were mapped on state, private, tribal, or other non-federal land classes (Table 2), but it could have been implemented with more time and resources.

Our spatial prioritization of management actions under the climate-informed strategy was based on anticipated climate suitability for WBP and other factors influencing WBP populations. Climate suitability for either the management target alone and other drivers has been suggested as a useful filter for spatial prioritization of adaptation actions (Cole et al. 2011; Hansen et al. 2016; Hennon et al. 2012; Serra-Varela et al. 2017). We extended this approach and drew on the conceptual model of direct and indirect effects of climate change on WBP to identify criteria for spatial allocation of management actions. Ideally, we would include spatial predictions of the direct future climate impacts on WBP itself, as well as the indirect effects of climate change on competing tree species, mountain pine beetles, blister-rust, and fire. However, spatially explicit maps of future climate impacts were unavailable for white pine blister-rust and fire. Spatial projections of mountain pine beetle survival and associated WBP mortality have been developed for the Greater Yellowstone (Buotte et al. 2016), but they did not cover the full extent of the ecosystem, which we required to be able to incorporate possible shifts in climate suitability for both WBP and mountain pine beetles. Species distribution models (SDMs) have been used to map projected climate suitability for both WBP (Chang et al. 2014) and its primary competitors (Douglas-fir, Engelmann spruce, subalpine fir, lodgepole pine; Piekielek et al. 2015) for each of three selected global climate models (GCMs). Thus, our criteria for the placement of management actions across the landscape were WBP climate suitability and future competition risk (Table 3). As spatial projections of climate change impacts on white pine blisterrust, fire, or beetles become available, such projections could be incorporated into our approach to improve prioritization of where to place treatments.

The first step in the development of our climate-informed management strategies was to map future climate suitability 


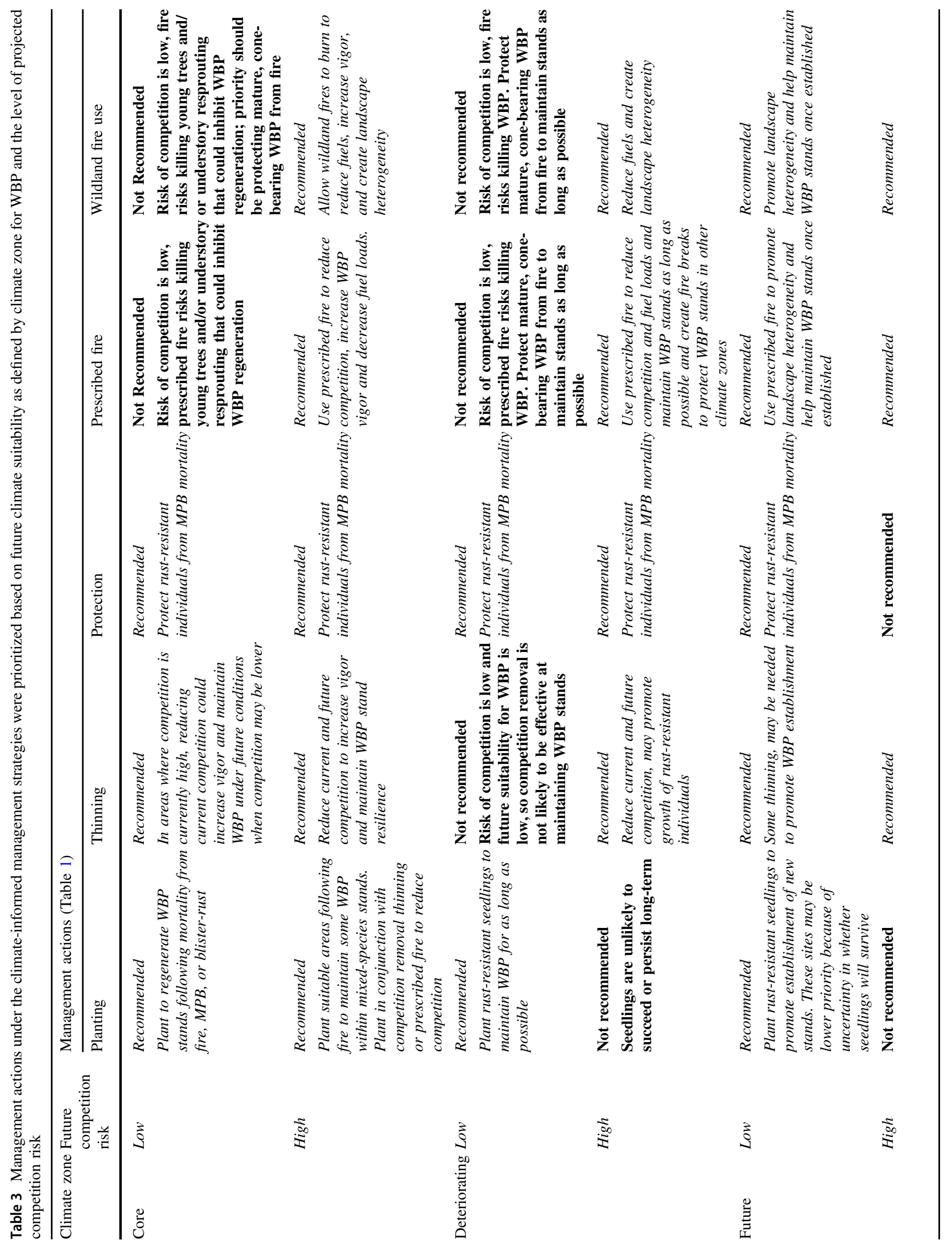


zones for WBP (Online Resource 1). We used the historical and future SDMs for WBP developed by Chang et al. (2014) to map zones of core, deteriorating, and future WBP climate suitability (following Hansen et al. 2016) for each of three GCMs and three time periods (see Online Resource 1). Locations where the climate is currently suitable and the climate is projected to remain suitable for WBP were "Core zones". Currently suitable locations that are projected to become less climatically suitable were labeled "deteriorating zones". "Future zones" were those areas, which are currently climatically unsuitable but are projected to improve in suitability in the future.

These zones of climate suitability for WBP were mapped for each of three future climate scenarios and three time periods of interest. For our future climate scenarios, we selected the three GCMs that bracket the range of potential future climate suitability for WBP in the GYE, representing the lowest (HadGEM2-ES), mid-range (CESM1-CAM5), and highest (CNRM-CM5) area of future suitable habitat for WBP (Online Resource 1; Chang et al. 2014). Climate suitability zones for each GCM were calculated for three future time periods of interest: 2010-2040, 2040-2070, and 2069-2099. These three time periods were selected to allow for both near-term and longer-term mapping of management options, since natural resource managers often must make management decisions on shorter time horizons than the century-scale predictions frequently reported in the scientific literature (Kemp et al. 2015). The temporal range of both the historical climate record and future projected climate is short (30-100 years) relative to the lifespan of WBP ( $>1000$ years), which admittedly limits our ability to detect changes in WBP populations (Keane et al. 2017). However, we were limited to available historical and future climate data and these projections provide a first step for understanding and managing whitebark pine response to climate.

Our next step was to use projections of climate suitability for competing tree species to further refine the spatial prioritization of management actions. We used SDMs for Douglas-fir, Engelmann spruce, subalpine fir, and lodgepole pine in the GYE (Piekielek et al. 2015) to map the area of "high" and "low" potential future risk of competition for WBP (Online Resource 1). We then combined the zones of future climate suitability for WBP with the mapped locations of high and low competition risk.

Finally, we worked with the GYCC Whitebark Pine Subcommittee to determine which management activities should be prioritized within each combination of the climate suitability zones for WBP (core, deteriorating, future) and potential future level of competition (low or high) from other species. The combination of the WBP climate suitability zones and future levels of competition resulted in six different mapped management regions ( 3 climate zones $\times 2$ competition levels). Through our discussions with the 
GYCC Whitebark Pine Subcommittee we determined which management actions should be available within each of these six management regions (Table 3). Based on these priorities, we then mapped the management actions available within each management region to develop spatial maps of each management action (Online Resource 1).

\section{Step 4. Evaluate Differences between Current Management and Climate-Informed Management}

Climate adaptation planning assumes that management actions will need to be modified from current management to mitigate climate change impacts. Modifications to management actions may take many forms. Examples include altering priorities from preserving species to preserving ecosystem function (Glick et al. 2011a), changing plant species seed mixes to facilitate expected transitions (Peterson et al. 2011), modifying thinning prescriptions to reduce fire risk (Peterson et al. 2011), or assisting migration of species to new habitats (e.g., Cole et al. 2011). In our case, the climate-informed management strategy deliberately prioritized actions in particular locations based on future climate projections. But, the climate-informed management permitted actions wherever those actions were considered likely to be effective at maintaining WBP forests, regardless of current constraints based on land status. Because future climate projections were not considered under the current management strategy and because the current strategy reflected current access and policy constraints, we expected there would be spatial differences in where each management strategy preferentially placed actions. We compared the total area and spatial patterns of the areas prioritized for each action (planting, thinning, mountain pine beetle protections, and fire use) under current management and the climate-informed management based on each GCM and time period.

More total land area in the GYE was prioritized for action under each of the climate-informed strategies than under the current strategy. The amount of area mapped for management action varied across the three GCMs and the time periods used to develop the three climate-informed strategies, but the climate-informed strategies prioritized at least one management action in $4429-4605 \mathrm{~km}^{2}$, compared to $2897 \mathrm{~km}^{2}$ under the current management strategy (Fig. 3a). Planting was prioritized in $3376-4181 \mathrm{~km}^{2}$ under climate-informed management, as opposed to $1661 \mathrm{~km}^{2}$ under current management (Fig. 3b). Similarly, more area was available under climate-informed management strategies than current management for thinning (climateinformed: 4291-4436 km², current: $2003 \mathrm{~km}^{2}$ ) and mountain pine beetle protection (climate-informed:
5918-6138 km², current: $2003 \mathrm{~km}^{2}$ current). Only fire use actions were higher under current management $\left(5920 \mathrm{~km}^{2}\right)$ than climate-informed management $\left(3,3665-4133 \mathrm{~km}^{2}\right)$.

The current and climate-informed management strategies also differed in their relative placement of actions with regard to both land classes and WBP climate suitability zones. The majority of the area that currently has a climate suitable for WBP is expected to deteriorate in climate suitability (mean across all climate scenarios = $17,876 \mathrm{~km}^{2}$ ). Over time, the area expected to decline in suitability increases while the area expected to maintain climate suitability (core zones) continues to decrease across all future climate scenarios (Fig. 4). As a result, management actions under both strategies were primarily located in areas of declining suitability for WBP (Fig. 5). However, the climate-informed strategies placed far more management actions in areas of core or future suitability than did the current strategy (Fig. 5).

The disparities in total land area and spatial patterns of locations prioritized for treatment were due to two related factors: (1) active management was permitted regardless of land class in the climate-informed management strategy but highly restricted under current management and (2) the locations where climate is expected to remain suitable for WBP in the future are disproportionately distributed in high elevation Wilderness lands where active management is not currently permitted. Reflecting current policy constraints, wildland fire use was the only management action permitted in Wilderness lands under the current management strategy. Active management actions (planting, thinning, and beetle protection) were only permitted in federal non-Wilderness lands near roads and trails. The climate-informed strategies were not similarly constrained because they were developed with the aim of maximizing WBP preservation and only considered future climate impacts while disregarding policy and access restrictions related to land class. Instead, the climate-informed strategies allowed for the most management actions in areas expected to maintain (core zones) or gain (future zones) climate suitability for WBP, while still permitting some actions in areas of declining climate suitability. Most of the area in core and future zones lies in Wilderness, with Wilderness comprising $68-74 \%$ and $78-80 \%$ of these zones, respectively (Fig. 6). As a result, the climate-informed management strategies prioritized more actions in Wilderness than did current management (Fig. 7). Because planting, thinning, and mountain pine beetle protection actions were allowed in both Wilderness and non-federal lands under the climate-informed strategies, the overall area considered for these actions was larger in the climate-informed strategies.

Under the climate-informed management strategies, the spatial placement of actions shifted as changing climate altered the location of climate suitability zones for WBP. 


\section{a)}

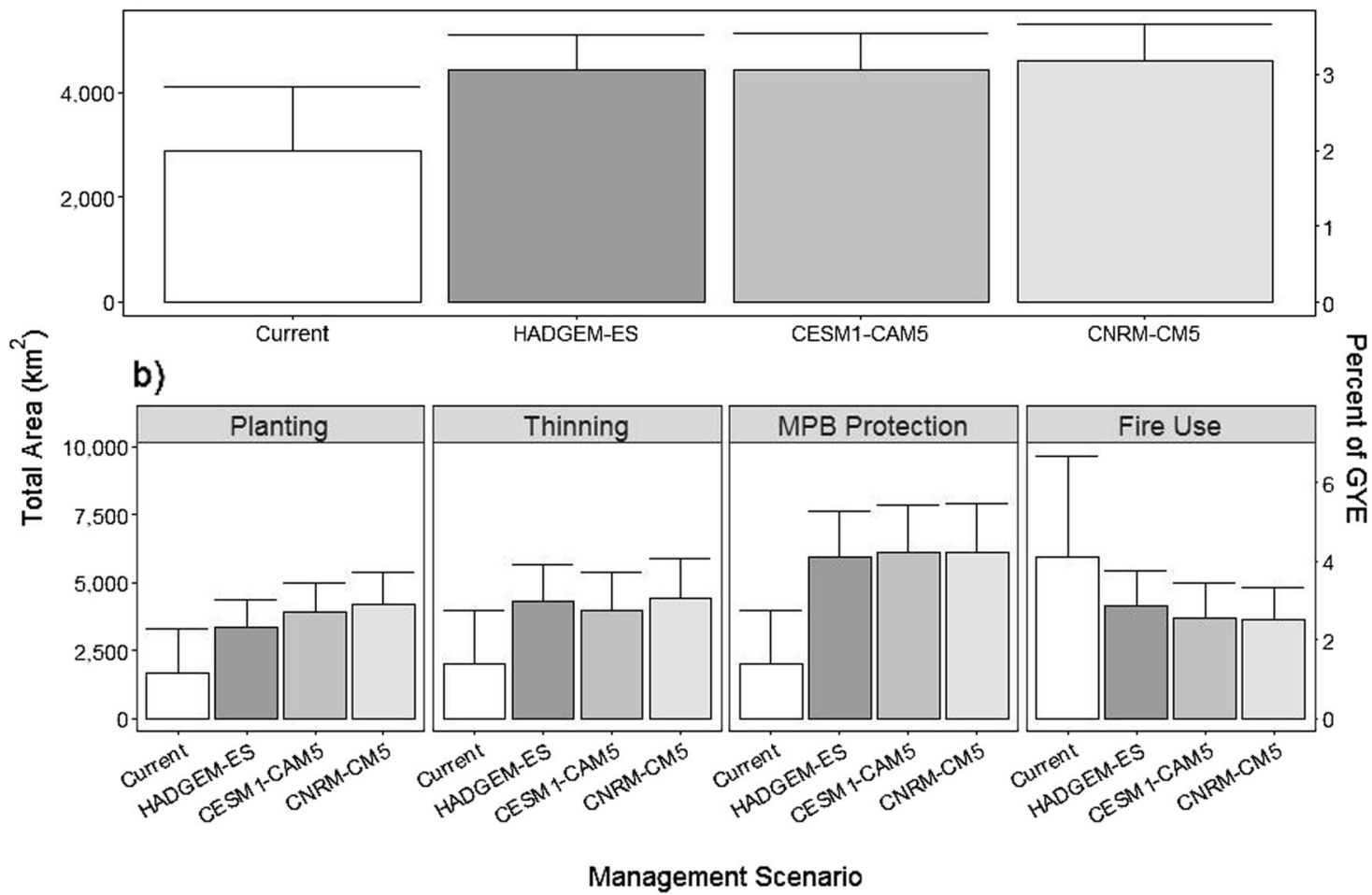

Fig. 3 The total area $\left(\mathrm{km}^{2}\right)$ where management actions were available differed between the current management strategy and the climateinformed strategies based on WBP climate suitability predictions using the three global circulation models considered (HADGEM-ES, CESM1-CAM5, and CNRM-CM5). Error bars show variation due to the three time periods considered (2010-2040; 2040-2070; 2069-2099). The management actions mapped included planting, thinning, mountain pine beetle protections (MPB Protection), and fire use (prescribed fire and wildland fire use). a Shows the total area where each management strategy allowed at least one of the management actions. b Shows the total area where each management action was permitted under the current management strategy and each of the climate-informed management strategies
Fig. 4 Time-series of changes in the total area of WBP climate suitability zones for each of three future climate scenarios

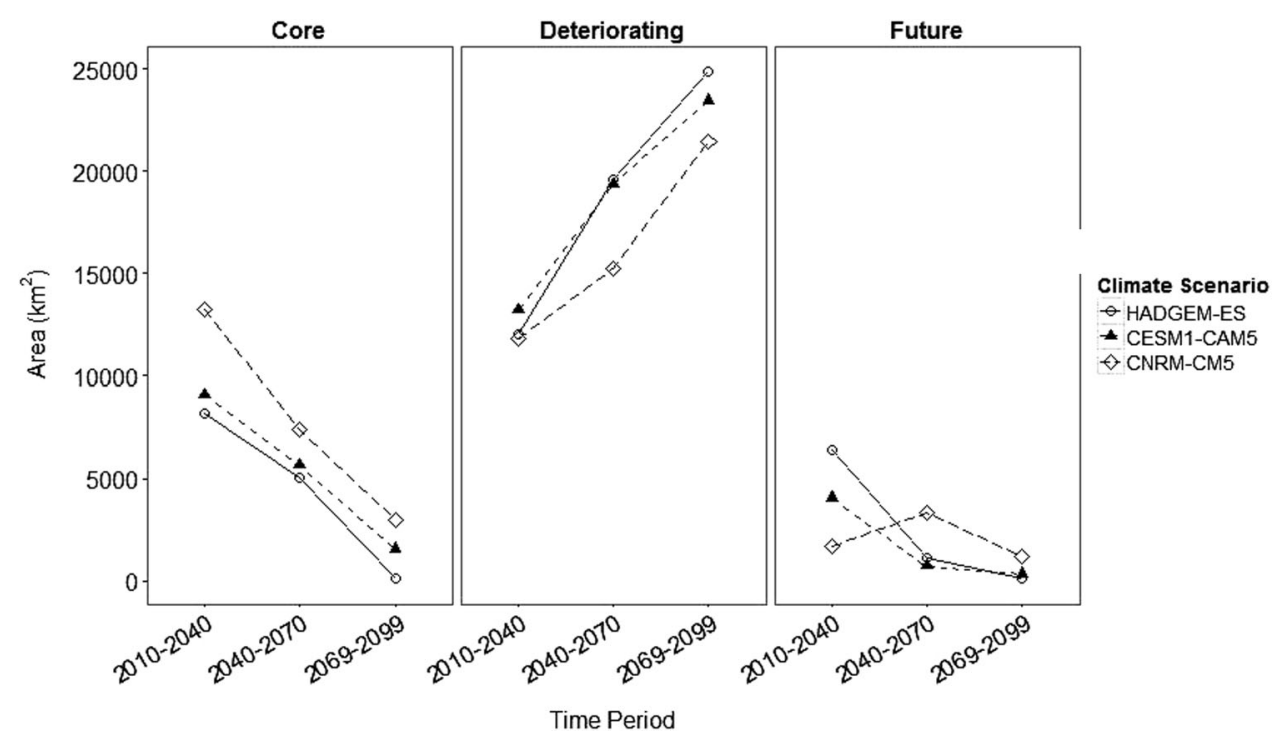

For example, planting actions as prioritized under climate-informed management for the climate scenario based on the CNRM-CM5 GCM shifted spatially within a watershed as climate change progressed through time
(Online Resource 2). However, under the current management strategy, the spatial placement of actions was static through time. Under all three climate scenarios considered, the area of core climate suitability zones declined through 

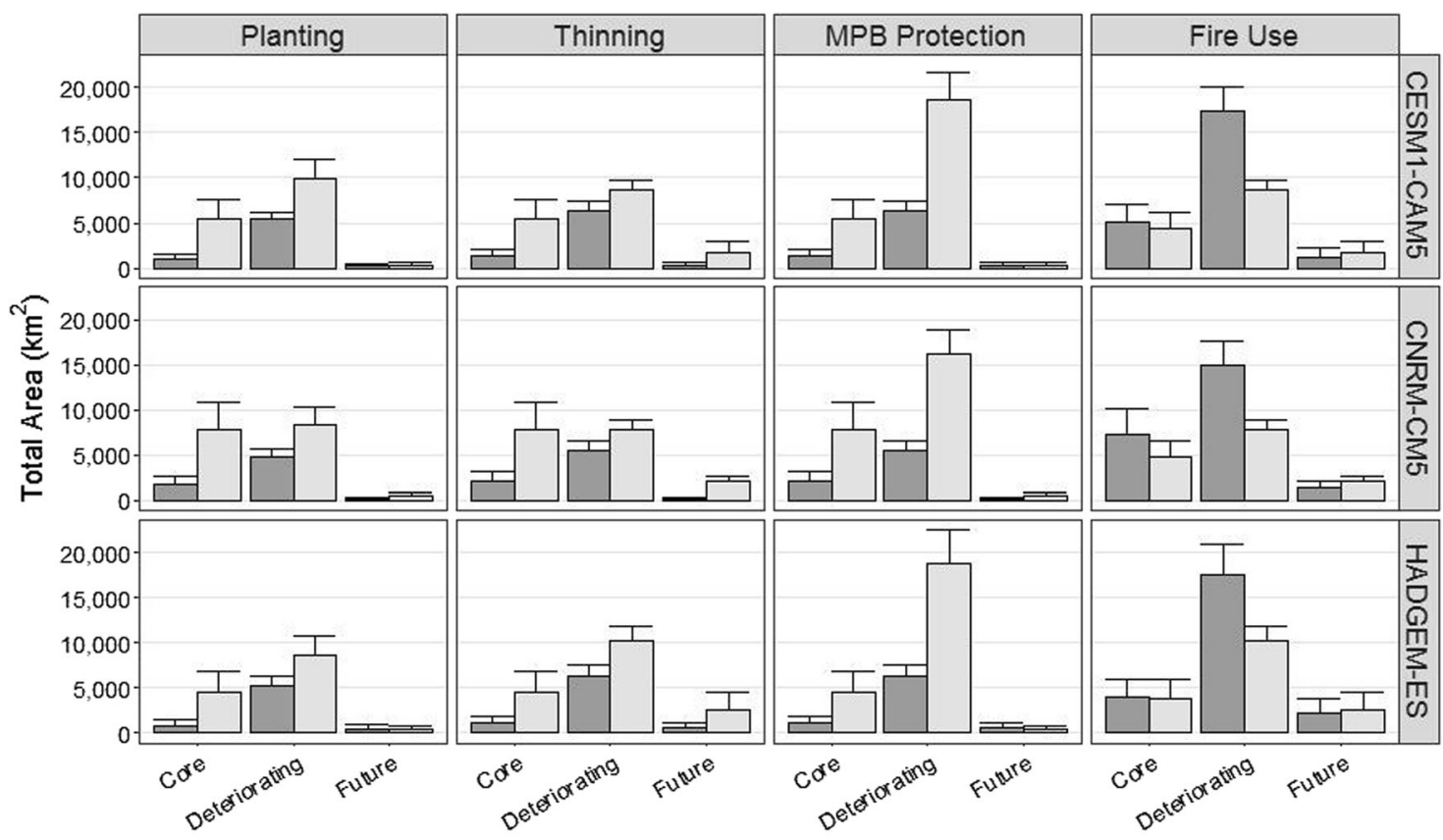

Climate Suitability Zone

$\square$ Current $\square$ Climate-informed

Fig. 5 Total area in each climate suitability zone mapped for each management action under current or climate-informed management for each of the three future climate scenarios. Climate zones were calculated for each future climate scenario based on that scenarios' projected suitability for WBP, so the area within each zone differs for each climate scenario. The areas shown are those for the climate scenario shown on the left axis

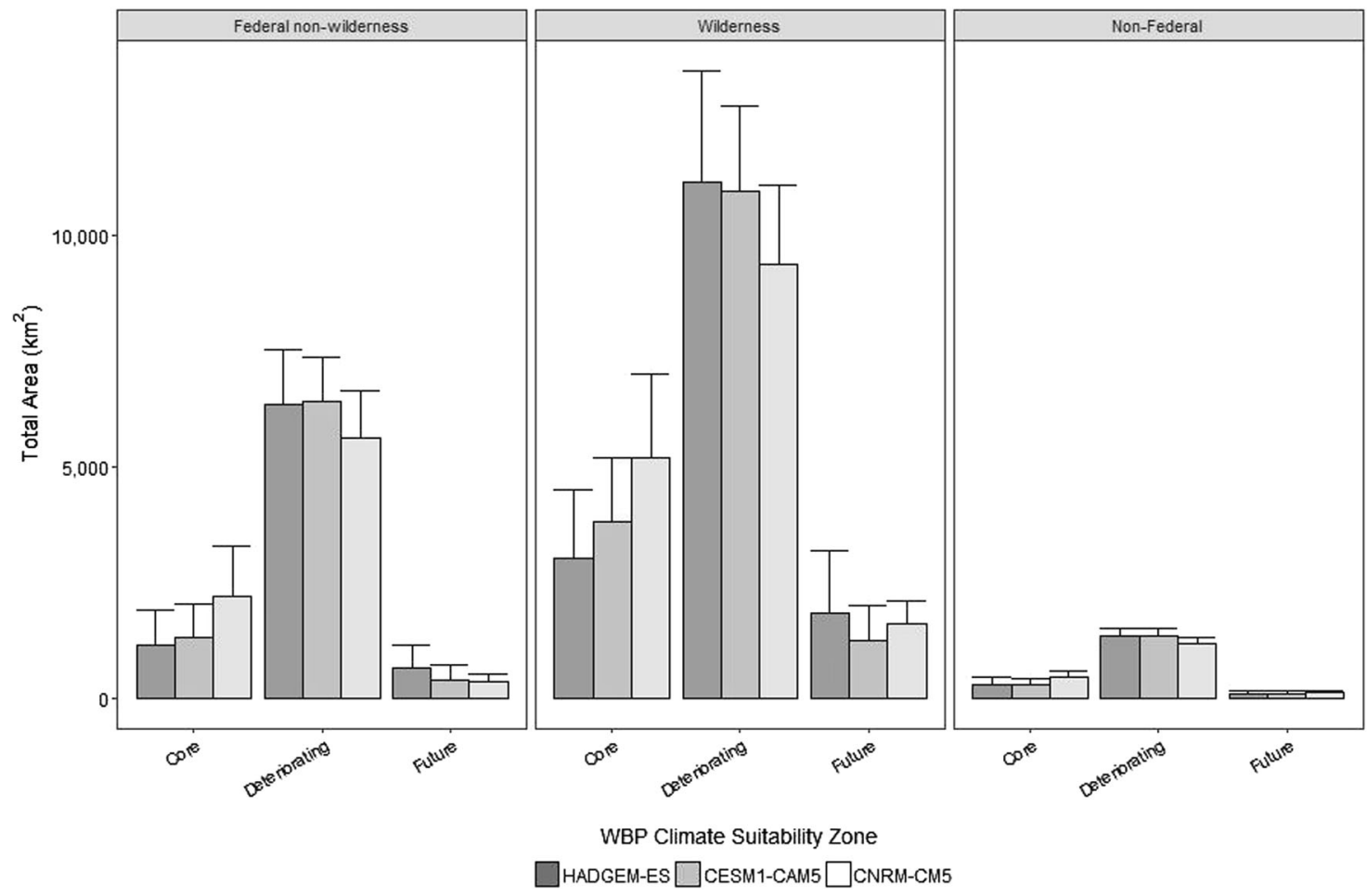

Fig. 6 The distribution of land classes with respect to WBP climate suitability zones helps to explain differences in the placement of management actions under current and climate-informed management strategies. The bars show the total area $\left(\mathrm{km}^{2}\right)$ within each climate suitability zone, which lies within the different land classes. Error bars represent variation through time since climate suitability zones were calculated for each of three time periods 


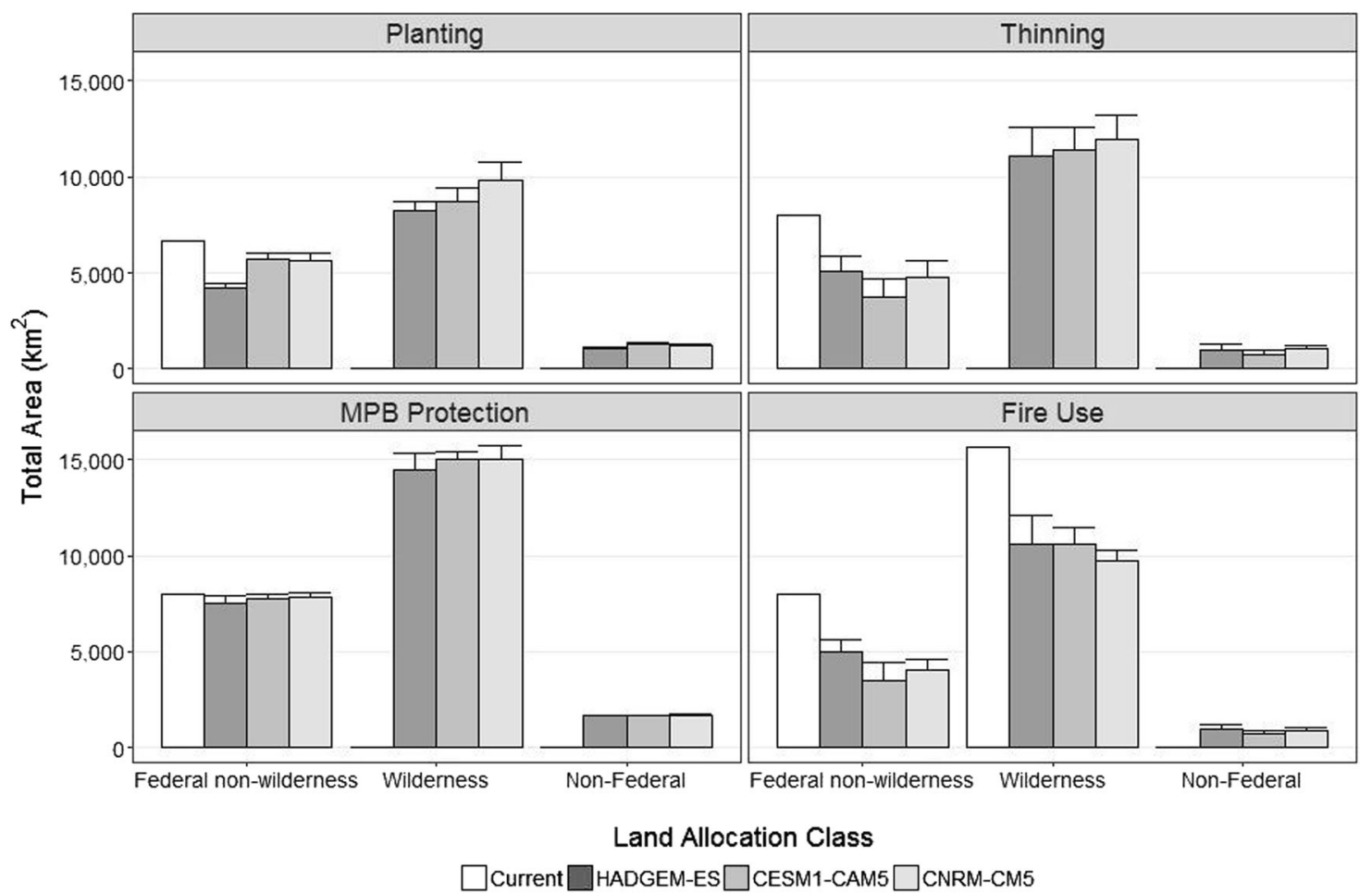

Fig. 7 Total area mapped for each management action within each land class under the current management strategy and climateinformed management for each of three future climate scenarios. Open bars represent management actions mapped under the current management strategy; shaded bars represent management actions

time, while the area of deteriorating climate suitability zones increased (Fig. 4). Since thinning and planting actions were primarily placed in core and future zones under the climate-informed strategies, the areas where these actions were prioritized generally shifted upwards in elevation, tracking suitable climate for WBP (Online Resource 2).

Despite the uncertainty in future climate projections, our three climate-informed management strategies identified locations of agreement in where to place management actions within the GYE. Agreement in where to plant remained fairly constant over time, while agreement in where to thin or use fire declined through time and increased for mountain pine beetle protection (Fig. 8). In general, the three climate scenarios agreed with one another more often than they agreed with the current management strategy in where to place management actions. However, in a small proportion of the landscape, all three climateinformed management scenarios agreed with current management in where to place management actions (Fig. 8). These areas represent places on the landscape where managers could consider implementing WBP management actions now that may enhance survival under future climate projections and encompass $1912 \mathrm{~km}^{2}$ (planting), $4423 \mathrm{~km}^{2}$ (thinning), $6265 \mathrm{~km}^{2}$ (mountain pine beetle protection), and $11,397 \mathrm{~km}^{2}$ (fire use) in just the first time period considered.

mapped under the climate-informed strategies based on projections from three global circulation models (HADGEM-ES, CESM1-CAM5, and CNRM-CM5). Error bars show variation due to the three time periods considered (2010-2040; 2040-2070; 2069-2099)

\section{Discussion}

Our goal was to develop an approach for spatially distributing climate adaptation actions for a species of concern across heterogeneous landscapes. We applied the approach to analyze differences between a management strategy for WBP developed by federal managers that does not consider climate change and one that we developed that was aimed at being effective under projected climate change. The comparison of these strategies provides insights into the opportunities and challenges of managing for climate adaptation in landscapes that are heterogeneous in topography, climate, and land class.

\section{Spatial Distribution of Management Actions}

The distribution of actions under the current management strategy may have implications for the long-term effectiveness of these management actions. The majority (68\%) of WBP's current distribution in the GYE occurs in federally designated or proposed wilderness areas, where management options are currently limited (Hansen et al. 2016). Further, 23\% of WBP currently occurs in Inventoried Roadless areas, where access makes planting or mechanized thinning logistically difficult (Hansen et al. 2016). Yet, 


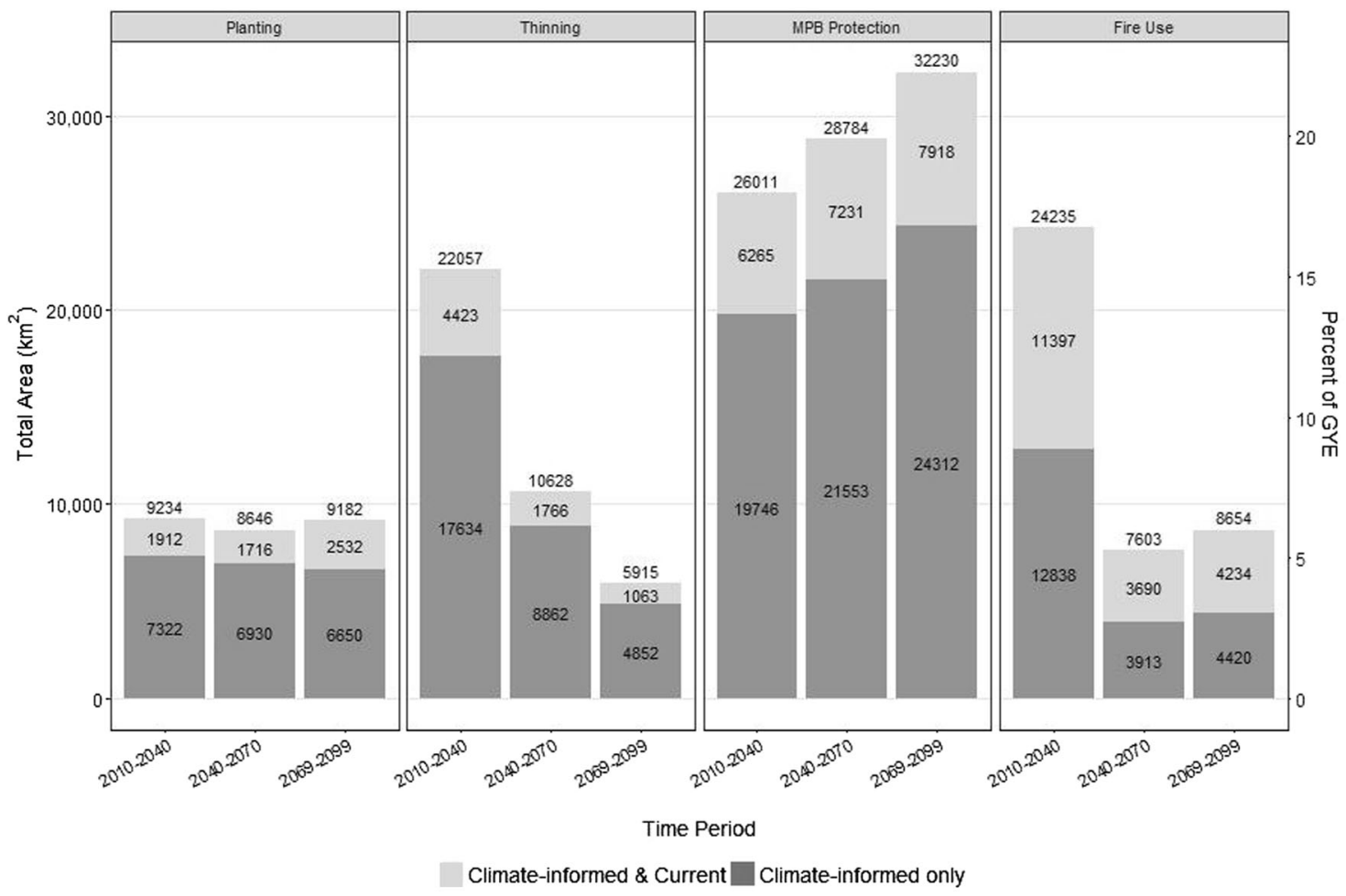

Fig. 8 Total area in the GYE study area where (1) the location of actions under the climate-informed management strategy agreed under all three future climate scenarios but did not agree with current management (dark gray) and (2) where management under all three future climate scenarios agreed with one another and with current

these are the areas where climatic conditions are most likely to remain suitable for WBP. Most of the federal nonwilderness lands where active management is currently feasible were projected to deteriorate in climate suitability for WBP by 2100; therefore, these may not be the locations where management actions will be most likely to contribute to conservation of WBP populations into the future.

Our climate-informed strategies generally prioritized active management actions in Wilderness areas of the GYE, but these strategies ignore management and logistical constraints. Active management actions (planting, thinning, and MPB protection), as well as fire use, were placed predominantly in Wilderness areas under the climate-informed strategies since that was where most of the core and future WBP climate suitability zones were located. However, under current land management policy, the only WBP management activities currently allowed in Wilderness are monitoring and inventory, cone collection from blister-rustresistant trees, and allowing for some controlled wildfires (Keane et al. 2012). The debate over whether climate change should lead toward more active management in Wilderness is ongoing. Landres (2010) outlined several arguments for a "hands-off" approach to management in wilderness areas even under changing climate, such as reducing unintended consequences, allowing for

management (light gray). Labels are the total area of agreement between climate-informed strategies, agreement between climateinformed and current management, and the total agreement (which would be the total area where all three climate-informed strategies agree), respectively

evolutionary change, and sustaining non-focal species, among others. Others have argued that, under changing climate, the maintenance of "primeval character" and "natural conditions" referenced in the Wilderness Act of 1964 will be impossible without some management intervention (Stephenson and Millar 2012). In particular, Keane (2000) notes that over half of WBP distribution nationally lies in Wilderness and suggests that current restrictions in Wilderness (i.e., prohibitions on planting blister-rustresistant seedlings) could limit the long-term success of restoration efforts. In a practical sense, the lack of roads in Wilderness presents a logistical challenge to access and implement many management actions. The placement of actions under the climate-informed strategy highlights the need for continued conversations between land managers, scientists, and policy makers regarding desired conditions and allowable management activities within wilderness lands.

\section{Adaptive Management}

The great uncertainty in future climate projections represents a major impediment to implementation of climate adaptation. Sources of this uncertainty include variations in projected future climate between different GCM models and 
emission scenarios, the downscaling of GCM projections to scales useful for management, ambiguity in climate impacts on species or resources, and likely effectiveness of management actions in a changing climate (Lawler et al. 2010). Addressing uncertainty in climate adaptation will require a flexible approach to management, where actions can be applied and monitored for their effectiveness and management strategies and goals re-evaluated as we learn (Hansen et al. 2016; Lawler et al. 2010). An adaptive management approach based on the work of Holling (1978) and Walters (1986) is increasingly being adopted by resource managers and conservation planners and recognized as necessary to climate adaptation planning (Lawler et al. 2010; The Conservation Measures Partnership 2008). However, the level of uncertainty amongst actions aimed at climate adaptation varies, where some management strategies will have a low degree of uncertainty while others will have a higher level of uncertainty (Lawler et al. 2010). Those management strategies with the lowest uncertainty and highest potential benefit represent the low-hanging fruit that could be implemented, monitored, and learned from first. Strategies with more uncertain outcomes will need to be applied in a more limited, experimental manner and phased in to place actions in more places across the landscape as monitoring allows for the evaluation of which and where actions are likely to be most effective.

Adaptive management will also be required as the location of where actions are recommended on the landscape shifts through time. The areas where planting might be recommended at the end of the century, for example, are not necessarily the same locations where planting might be most suitable at mid-century. For example, WBP seedlings may not be able to survive the near-term harsh winter conditions that currently predominate upper timberline sites, even if those sites are projected to be suitable by 2100 (Keane et al. 2017), so planting may be inappropriate there until the climate has changed to make conditions suitable to seedling survival. Our analysis highlights the need to phasein where climate adaptation actions occur as climate change progresses and to monitor whether actions that made sense under one set of climate conditions are still suited to an altered climate.

Our mapped strategies allowed us to identify areas of higher and lesser agreement between each of our management strategies. Some management actions, often called "no-regrets" management decisions, can be expected to have a variety of benefits regardless of future climate conditions (Millar et al. 2014; Swanston and Janowiak 2012). Our prioritization efforts identified locations where management under all three climate scenarios agreed with management priorities under current management; these areas represent locations to prioritize initial implementation efforts and monitor these actions. For example, planting of blister-rust-resistant WBP seedlings is promoted as the key management action to restore WBP throughout its range (Keane et al. 2017, 2012). All three of our climate-informed management strategies agreed with current management in where to prioritize planting in $6-10 \%$ (depending on time period) of the landscape. These are the locations that could be prioritized for further investigation as to whether they are truly appropriate for planting actions. Our mapped strategies help to identify the general locations where actions may be most effective, but some further refinement of where to actually implement actions may be necessary. Targeting recently burned areas within WBP's upper elevational limits for WBP planting actions is recommended because both the scientific literature and simulation modeling suggest those are the locations where planting will be most effective (Keane et al. 2016, 2017). Further, implementation of the management actions will have to rely on local site or standlevel conditions. Planting of blister-rust-resistant seedlings should be focused on microsites affording some protection from wind and sun, such as in the lee of rocks, stump or logs and planting in proximity to sapling or mature WBP trees increases the likelihood that suitable mycorrhizal communities will be present in the soil (Keane et al. 2017).

All three of our climate-informed management strategies agreed in a surprisingly large number of places across the GYE. These locations where climate-informed strategies agreed but disagreed with current management could be prioritized for experimental testing of management actions. But, to move forward with experimental actions would require modifications to current land management policies, partnerships with non-federal landowners, or the ability to implement actions in difficult to access locations. These locations represent good candidates for experimental management approaches to evaluate how well management actions can mitigate current and future threats to WBP. For example, planting could represent a first step toward adaptive management. Planting actions were prioritized in $7322 \mathrm{~km}^{2}$ under all three climate-informed strategies in the near-term time period (2010-2040). These were locations where current management did not prioritize planting. The climate-informed strategies prioritized planting in all core zones and in future and deteriorating zones with low future competition risk. Planting was permitted under the current strategy on non-wilderness federal lands within one-mile of roads and trails. Therefore, where climate-informed strategies agreed with one another and prioritized planting on non-wilderness lands in core zones, there may be an opportunity for experimental planting actions. Cost and access may be the prohibitive factors, since these locations are greater than one-mile from roads or trails as identified under the current management strategy. Some limited planting experiments, focused on core zones that are most 
easily accessed may be the best candidates for experimental actions.

However, often the reason for the disagreement between climate-informed strategies and the current management strategy lies in management policies amongst the different land classes. Under the climate-informed strategies, all core and future WBP zones were prioritized for thinning actions, but under the current strategy only federally owned, nonwilderness, multiple use forests were considered for thinning. Therefore, areas prioritized for thinning where the climate-informed strategies disagreed with current management were in either Wilderness or non-federal lands. To apply experimental thinning actions would either require modifications to which management actions are permitted in Wilderness or working with non-federal partners to test actions on state, tribal, or private lands. Strong public support exists for active management of WBP on federal lands in the GYE, including Wilderness (Shanahan 2015), and legally some such actions may be permissible if the right procedures are followed (Long and Biber 2014). Alternatively, the areas where climate-informed strategies disagreed with current management on where to prioritize wildland fire use were primarily on non-federal lands. Here, the challenge lies in whether private, tribal, or state landowners would be willing to permit wildfires to burn on these lands, which represent a small total area $\left(<1200 \mathrm{~km}^{2}\right)$.

\section{Concluding Comments}

This effort represents a first attempt at spatially incorporating expected climate impacts to both a management target (WBP) and one of its drivers (competition) into climate change adaptation planning. As projections of climate impacts on ecosystems have proliferated, so has recognition of the need to incorporate climate change into natural resource management (Archie et al. 2012; Lemieux et al. 2013; Mimura et al. 2014; West et al. 2009). In recent years, a number of conceptual frameworks, adaptation planning guidebooks, and decision-support frameworks for climate adaptation planning have been developed (e.g., Cross et al. 2012b; Mimura et al. 2014; Peterson et al. 2011, 2003; Stein et al. 2014; Swanston and Janowiak 2012). The challenge to implementing adaption plans, however, is how to determine where exactly adaptation actions should be placed in a landscape so they will be most effective into the future.

We built upon previous climate adaptation tools by adding spatial context to management strategies to address climate change. By focusing on the steps of assessing climate change impacts, and identifying and prioritizing management actions of the climate adaptation planning cycle, we developed a method for developing spatial climate adaptation plans for specific management actions. We applied our method for spatial prioritization planning to WBP in the GYE, which had been identified as a management resource of interest and for which detailed management objectives under current climate conditions had been developed by the GYCC WBP Subcommittee (GYCC WBSC 2011). To add specificity and spatial context to this process, we used spatial projections of direct and indirect climate impacts and close partnerships with natural resource managers to spatially allocate management actions aimed at mitigating the threats to WBP. The end results were spatial maps of the locations where management actions could be prioritized, essentially maps for the managers' "toolkit" to select from and implement based on local stand-level conditions. Because of the uncertainties in future climate projections and management constraints that may limit implementation of actions, monitoring and evaluation of actions will be necessary to learn from any implemented actions and modify future prioritization of management actions. This method for prioritizing locations for climate adaptation actions could be applied to any resource for which information regarding climate vulnerability and climate-mediated risk factors are available.

Our climate adaptation planning for WBP was specific to the GYE. This method could be adapted to other portions of the species' range, but would likely need to be regionally specific. Keane et al. (2017) found that rates and magnitudes of decline vary widely across WBP's range in the Northern Rocky Mountains. Landscapes that have limited WBP forests are probably more vulnerable because there are few places the species can migrate to or maintain populations. Landscapes with little rust infection, such as the GYE, may have a higher chance of regeneration in the short term, but the high levels of mortality from mountain pine beetles may have removed many rust-resistant individuals. It is difficult to evaluate the prognosis of WBP across the landscapes in its range because of the unique interaction of the numerous factors influencing its future populations (Keane et al. 2017). Future research to evaluate regionspecific interactions between climate change and these drivers of WBP population dynamics is a needed first step toward extending climate adaptation planning to other locations within WBP's range. However, we felt that the GYE served as a good example landscape for developing spatial climate adaptation plans for the species because over half of the aerial extent of WBP in the US is found within the GYE (Hansen et al. 2016). Additionally, WBP populations in the region have been particularly hard hit by recent mountain pine beetle mortality, with over $95 \%$ mortality of cone-bearing trees (Hansen et al. 2016). Finally, because well-developed management plans for current conditions had already been developed for WBP in the region we were able to incorporate climate change impacts into these existing management plans. 
Our method can be improved as projections of future climate impacts improve. We were only able to include climate suitability for WBP and competition from other tree species in developing our climate-informed management strategies, due to the lack of spatially explicit projection of climate impacts on the other drivers of WBP dynamics (blister-rust, mountain pine beetle, and wildfire). Additionally, our spatial prioritization was based on SDM modeling for WBP and its competitors. There are several limitations to using SDM models to project climate impacts, including their failure to include biotic interactions, dispersal, and disturbance (Pearson and Dawson 2003). We attempted to incorporate competition by including SDM projections of climate impacts to competing conifer species. However, process-based models where competition between species is an emergent property of individual species' responses to changing climate and resource conditions could reveal very different projected climate impacts to both WBP and the other tree species. Process-based models allow for more complex projections of the impacts of competition, disturbance, and management (Keane et al. 2011) and would improve upon the prioritization of management actions. However, sufficient data are rarely available to validate such simulation models run over large landscapes and long time frames (Keane et al. 2011; Perry and Enright 2006), contributing to higher levels of uncertainty in model results. Use of both SDMs and process-based projections of climate impacts to the management target and climate-mediated drivers would improve the development of climateinformed management strategies.

A strong partnership between scientists and managers was integral to our method such that managers guided the design, selection, and spatial prioritization of different management actions based on the identified climate impacts. Our effort to engage with resource managers to develop a spatial adaptation plan was successful at building partnerships and prioritizing where on the landscape the managers felt different tools would be most useful for managing WBP forests. The two management strategies we developed highlight important differences in terms of the spatial distribution of where management actions might be prioritized. But, actual implementation of the management actions would need to be based on site and stand-level conditions within these general management zones. Our current results represent only "toolboxes" from which managers might select different actions, but do not yet tell us how the differences between the current and climateinformed management strategies might translate into differences in the long-term viability of WBP populations. It is possible that not all the area prioritized for action in the climate-informed strategies would need to be treated to successfully maintain WBP populations. The current management strategies could potentially be treating enough area to keep WBP populations on the landscape. As a result of the partnerships we developed through this project, we continue to work with the GYCC WBP subcommittee to better evaluate these differences. Our next step is to simulate implementation of the current and climate-informed management strategies under each climate change scenario, using the landscape simulation model FireBGCv2 (Keane et al. 2011). These simulations will allow us to better evaluate how the different strategies perform in terms of distribution, structure, and demographics of WBP populations in the GYE and bring this information back to the managers to inform their management planning.

The method developed here to spatially prioritize climate adaptation actions is broadly applicable to other species, resources, and geographic locations. For example, many other tree species are likely to be vulnerable to climate change. Coops and Waring assessed the vulnerability of 15 tree species in the Pacific Northwest region of North America and found that 9 of the 15 species were expected to decrease in climatically suitable range (Coops and Waring 2011). Climate adaptation planning has been developed for a wide variety of species and resources, just a few example include: Bonneville cutthroat trout in Utah, Wyoming and Idaho (Cross et al. 2012a), Joshua trees in California (Cole et al. 2011), and fire regimes in British Columbia (Nitschke and Innes 2008), and a wide variety of forest planning decisions in Olympic National Forest and Tahoe National Forest (Littell et al. 2011). To illustrate, consider climate adaptation planning for quaking aspen (Populus tremuloides), a species expected to be vulnerable to future climate change across much of its range (Worrall et al. 2013). In step 1, direct effects of climate on aspen might include changes in drought frequency or the occurrence of late season frost events; indirectly, climate change could influence aspen populations through alteration of fire regimes, changes to the distribution or productivity of competing conifer species, or increases in the incidence of fungal diseases (Worrall et al. 2013). Prescribed fire, clearfell cutting and selective thinning treatments to reduce competition and increase aspen vigor (Shepperd 2004), and even assisted migration (Gray et al. 2011) are examples of management actions that might be considered during step 2 . For step 3, spatially explicit projections of climate-induced changes in the distribution of aspen itself, competing conifer species, fire frequency and severity, the potential for extreme weather events (droughts, frost), and incidence of fungal diseases are examples of the types of data that could be included in spatially explicit adaptation planning. In step 4 , current management is compared with potential changes to management based on incorporation of climate impacts. In some areas climate-induced changes in fire frequency could favor aspen regeneration, spatial maps of where these locations might best promote aspen regeneration could 
assist in determining where to promote wildland fire use or consider building ungulate exclosures to protect aspen sprouts from herbivory. Our approach can be adapted to any management target for which a conceptual model of the direct and indirect effects of climate change can be developed and where spatial predictions of at least some of those drivers are available.

Acknowledgements We would like to thank the Greater Yellowstone Coordinating Committee's Whitebark Pine Subcommittee for providing data, guidance on development of our spatial prioritization, and feedback on both mapping efforts as well as early manuscript drafts. Ellen Jungck, the chair of the Subcommittee, was especially helpful in coordinating meeting and information sharing with the Subcommittee. Tony Chang and Nate Piekielek provided spatial predictions of climate suitability for whitebark pine and other tree species in the GYE. Tony Chang, additionally, provided assistance with developing analysis methods. Linda Phillips assisted with analysis of land classes within whitebark pine's current distribution. Comments by two anonymous reviewers improved the manuscript. Funding was provided by the North Central Climate Sciences Center, the Montana NSF EPSCoR Initiative, and the Great Northern Conservation Cooperative (F15AC01086).

\section{Compliance with ethical standards}

Conflict of interest The authors declare that they have no conflict of interest.

\section{References}

Allen CD et al. (2010) A global overview of drought and heat-induced tree mortality reveals emerging climate change risk for forests. For Ecol Manag 259:660-684

Archie KM, Dilling L, Milford JB, Pampel FC (2012) Climate change and western public lands: a survey of U.S. federal land managers on the status of adaptation efforts. Ecol Soc 17:20. https://doi.org/ 10.5751/es-05187-170420

Arno SF, Hoff RJ (1989) Silvics of whitebark pine (Pinus albicaulis). U.S. Department of Agriculture, Forest Service, Intermountain Research Station, Ogden, Utah, General Technical Report INT253

Bell DM, Bradford JB, Laurenroth WK (2013) Early indicators of change: divergent climate envelopes between tree life stages imply range shifts in the western United States. Glob Ecol Biogeogr 23:168-180

Bentz BJ et al. (2010) Climate change and bark beetles of the western United States and Canada: direct and indirect effects. Bioscience 60:602-613

Bierbaum R et al. (2013) A comprehensive review of climate adaptation planning in the United States: more than before, but less than needed. Mitig Adapt Strateg Glob Change 18:361-406

Buotte PC, Hicke JA, Preisler HK, Abatzoglou JT, Raffa KF, Logan JA (2016) Climate influences on whitebark pine mortality from mountain pine beetle in the Greater Yellowstone Ecosystem. Ecol Appl 26:2507-2524. https://doi.org/10.1002/eap.1396

Chang T (2015) Historic and projected climate change in the Greater Yellowstone Ecosystem. Yellow Sci 23:14-19

Chang T, Hansen AJ (2015) Historic and projected climate change in the Greater Yellowstone Ecosystem. Yellow Sci 23:14-19

Chang T, Hansen AJ, Piekielek N (2014) Patterns and variability of projected bioclimatic habitat for Pinus albicaulis in the Greater
Yellowstone Area. PLoS ONE 9:e111669. doi:111610.111371/ journal.pone.0111669

Cole KL, Ironside K, Eischeid J, Garfin G, Duffy PB, Toney C (2011) Past and ongoing shifts in Joshua tree distribution support future modeled range contraction. Ecol Appl 21:137-149. https://doi. org/10.1890/09-1800.1

Coops NC, Waring RH (2011) Estimating the vulnerability of fifteen tree species under changing climate in Northwest North America. Ecol Modell 222:2119-2129

Crookston NL, Rehfeldt GE, Dixon GE, Weiskittel AR (2010) Addressing climate change in the forest vegetation simulator to assess impacts on landscape forest dynamics. For Ecol Manag 260:1198-1211

Cross MS, McCarthy Pd, Garfin G, Gori D, Enquist CAF (2012a) Accelerating adaptation of natural resource management to address climate change. Conserv Biol 27:4-13

Cross MS et al. (2012b) The Adaptation for Conservation Targets (ACT) Framework: a tool for incorporating climate change into natural resource management. Environ Manag 50:341-351

Despain D (1990) Yellowstone Vegetation. Consequences of environment and history in a natural setting. Roberts Rhinehart, Boulder, CO, USA

Geils BW, Hummer KE, Hunt RS (2010) White pines, Ribes, and blister rust: a review and synthesis. For Pathol 40:147-185

Glick P, Chmura H, Stein BA (2011a) Moving the conservation goal posts: a review of climate adaptation literature. National Wildlife Federation, Washington, DC, USA

Glick P, Stein BA, Edelson N (2011b) Scanning the conservation horizon: a guide to climate change vulnerability assessment. National Wildlife Federation, Washington, DC, USA

Gray LK, Gylander T, Mbogga MS, Chen P-y, Hamann A (2011) Assisted migration to address climate change: recommendations for aspen reforestation in western Canada. Ecol Appl 21:1591-1603. https://doi.org/10.1890/10-1054.1

Greater Yellowstone Coordinating Committee Whitebark Pine Subcommittee (GYCC WBSC) (2011) Whitebark Pine Strategy for the Greater Yellowstone Area. Greater Yellowstone Coordinating Committee, Bozeman, MT

Halofsky JE, Peterson DL (2016) Climate change vulnerabilities and adaptation options for forest vegetation management in the northwestern USA. Atmosphere 7 https://doi.org/10.3390/a tmos7030046

Hansen AJ, Ireland KB, Legg K, Keane RE, Barge E, Jenkins MB, Pillet M (2016) Complex challenges of maintaining whitebark pine in Greater Yellowstone under climate change: a call for innovative research, management, and policy approaches. Forests 7:54. https://doi.org/10.3390/f7030054

Hansen AJ, Phillips L (2015) Which tree species and biome types are most vulnerable to climate change in the US Northern Rocky Mountains? For Ecol Manag 338:68-83

Hansen L, Gregg RM, Arroyo V, Ellsworth S, Jackson L, Snover A (2013) The state of adaptation in the United States: an overview. A report for the John D. and Catherine T. MacArthur Foundation. Ecoadapt, Bainbridge Island, WA, USA

Hatala JA, Dietze MC, Crabtree RL, Kendall K, Six D, Moorcroft PR (2010) An ecosystem-scale model for the spread of a host-specific forest pathogen in the Greater Yellowstone Ecosystem. Ecol Appl 21:1138-1153

Heller NE, Zavaleta ES (2009) Biodiversity management in the face of climate change: a review of 22 years of recommendations. Biol Conserv 142:14-32

Hennon PE, D'Amore DV, Schaberg PG, Witter PG, Shanley CS (2012) Shifting climate, altered niche, and a dynamic conservation strategy for yellow-cedar in the North Pacific coastal rainforest. Bioscience 62:147-158 
Holling CS (1978) Adaptive environmental assessment and management. John Wiley and Sons, New York, NY

IPCC (2014) Climate Change 2014: Synthesis Report. Contribution of working groups I, II, and III to the Fifth Assessment Report of the Intergovernmental Panel on Climate Change. IPCC, Geneva, Switzerland

Jacobs J, Weaver T (1990) Effects of temperature and temperature preconditioning on seedling performance of whitebark pine. In: Schmidt WC, McDonald KJ (eds) Symposium on whitebark pine ecosystems: ecology and management of a high-mountain resource. U.S. Department of Agriculture, Forest Service, Intermountain Research Station, Ogden, UT, USA, pp. 134-139. General Technical Report INT-GTR-270

Keane RE (2000) The importance of wilderness to whitebark pine research and management. Proceedings of the symposium: Wilderness Science: In a time for change. Volume 3: Wilderness as a Place for Scientific Inquiry. McCool, Stephen F, Cole David N, Borrie, William T, O'Loughlin, Jennifer (eds). USDA Forest Service, Missoula, MT, USA, pp. 84-93. General Technical Report RMRS-P-15-VOL-3

Keane RE, Holsinger LM, Mahalovich MF, Tomback DF (2016) Evaluating future success of whitebark pine ecosystem restoration under climate change using simulation modeling. Restor Ecol 25:220-233

Keane RE, Holsinger LM, Mahalovich MF, Tomback DF (2017) Restoring whitebark pine ecosystems in the face of climate change. U.S. Department of Agriculture, Forest Service, Rocky Mountain Research Station, Fort Collins, CO, USA, General Technical Report RMRS-GTR-361

Keane RE, Loehman RA, Holsinger LM (2011) The FireBGCv2 landscape fire succession model: a research simulation platform for exploring fire and vegetation dynamics. United States Department of Agriculture, Forest Service, Rocky Mountain Research Station, Fort Collins, CO, General Technical Report255

Keane RE et al. (2012) A range-wide restoration strategy for whitebark pine (Pinus albicaulis). U.S. Department of Agriculture, Forest Service, Rocky Mountain Research Station, Fort Collins, CO, USA, General Technical Report RMRS-GTR-279

Kemp KB, Blades JJ, Klos PZ, Hall TE, Force JE, Morgan P, Tinkham WT (2015) Managing for climate change on federal lands of the western United States: perceived usefulness of climate science, effectiveness of adaptation strategies, and barriers to implementation. Ecol Soc 20:17. https://doi.org/10.5751/ES-07522200217

Kliejunas JT, Geils BW, Glaeser JM, Goheen EM, Hennon P, MeeSook K, Kope H, Stone J, Sturrock R, Frankel SJ (2009) Review of literature on climate change and forest diseases of western North America. U.S. Department of Agriculture, Forest Service, Pacific Southwest Research Station, Albany, CA, USA, General Technical Report PSW-GTR-255

Landres P (2010) Let it be: A Hands-off Approach to Preserving Wilderness in Protected Areas. In: Cole DN, Yung L (eds) Beyond Naturalness: Rethinking Park and Wilderness Stewardship in an Era of Rapid Change. Island Press, Washington, DC, USA, pp 88-105

Lawler JJ et al. (2010) Resource management in a changing and uncertain climate. Front Ecol Environ 8:35-43

Lemieux CJ, Thompson JL, Dawson J, Schuster RM (2013) Natural resource manager perceptions of agency performance on climate change. Environ Manag 114:178-189

Littell S, Peterson DL, Millar CI, O'Halloran KA (2011) U.S. National forests adapt to climate change through science-management partnerships. Clim Change https://doi.org/10.1007/s10584-0110066-0
Long E, Biber E (2014) The Wilderness Act and climate change adaptation. Environ Law 44:632-691

Marston RA, Anderson PD (1991) Watersheds and vegetation of the Greater Yellowstone Ecosystem. Conserv Biol 5:338-346

McKinney DW, Pedlar JH, Rood RB, Price D (2011) Revisiting projected shifts in the climate envelopes of North American trees using updated general circulation models. Glob Change Biol 17:2720-2730

Millar CI, Stephenson NL, Stephens SL (2007) Climate change and forests of the future: managing in the face of uncertainty. Ecol Appl 17:2145-2151

Millar CI, Swanston CW, Peterson DL (2014) Adapting to climate change. In: Peterson DL, Vose JM, Patel-Wynand T (eds) Climate change and United States forests. Ch. 8. Springer, Dordrecht, The Netherlands, pp. 183-222

Mimura $\mathrm{N}$ et al. (2014) Adaptation planning and implementation. In: Field CB et al. (eds) Climate Change 2014: Impacts, Adaptation, and Vulnerability. Part A: Global and Sectoral Aspects. Contribution of Working Group II to the Fifth Assessment Report of the Intergovernmental Panel on Climate Change. Cambridge University Press, Cambridge, United Kingdom and New York, NY, USA, pp. 869-898

Morelli TL, Yeh S, Smith N, Hennessy MB, Millar CI (2012) Climate project screening tool: an aid for climate change adaptation. U.S. Department of Agriculture, Forest Service, Pacific Southwest Research Station, Albany, CA, Res. Pap. PSW-RP-263

National Park Service (2013) Using scenarios to explore climate change: a handbook for practioners. National Park Service Climate Change Response Program, Fort Collins, CO

Nelson R, Cross MS, Hansen L, Tabor GM (2016) A three-step decision support framework for climate adaptation: selecting climate-informed conservation goals and strategies for native salmonids in the northern U.S. Rockies. Wildlife Conservation Society, EcoAdapt, Center for Large Landscape Conservation, Bozeman, MT, USA

Nitschke CR, Innes JL (2008) Integrating climate change into forest management in South-Central British Columbia: an assessment of landscape vulnerability and development of a climate-smart framework. For Ecol Manag 256:313-327

Ogden AE, Innes JL (2009) Application of structured decision making to an assessment of climate change vulnerabilities and adaptation options for sustainable forest management. Ecol Soc 14:1-11

Olliff ST, Monahan WB, Kelly V, Theobald DM (2016) Approaches, challenges, and opportunities for climate-smart adaptation. In: Hansen AJ, Monahan WB, Theobald DM, Olliff ST (eds) Climate change in wildlands: pioneering approaches to science and management. Ch. 13. Island Press, Washington, D.C

Pearson RG, Dawson TP (2003) Predicting the impacts of climate change on the distribution of species: are bioclimatic envelope models useful? Glob Ecol Biogeogr 12:361-371

Perry GLW, Enright NJ (2006) Spatial modelling of vegetation change in dynamic landscapes: a review of methods and applications. Progress Phys Geogr 30:47-72

Peterson DL, Millar CI, Joyce LA, Furniss MJ, Halofsky JE, Neilson RP, Morrelli TL (2011) Responding to climate change in National Forests: a guidebook for developing adaptation options. U.S. Department of Agriculture, Forest Service, Pacific Northwest Research Station, Portland, OR, Gen. Tech. Rep. PNW-GTR-855

Peterson GD, Cumming GS, Carpenter SR (2003) Scenario planning: a tool for conservation in an uncertain world. Conserv Biol 17:358-366

Piekielek N, Hansen AJ, Chang T (2015) Using custom scientific workflow software and GIS to inform protected area climate adaptation planning across the Greater Yellowstone. Ecol Inform 30:40-48 
Schrag AM, Bunn AG, Graumlich LJ (2008) Influence of bioclimatic variables on tree-line conifer distribution in the Greater Yellowstone Ecosystem: implications for species of conservation concern. J Biogeogr 35:698-710. https://doi.org/10.1111/j.13652699.2007.01815.x

Sepulveda AJ et al. (2015) The shifting climate portfolio of the Greater Yellowstone Area. PLoS ONE 10:e0145060. doi:0145010.0141371/journal.pone.0145060

Serra-Varela M, Alia R, Daniels RR, Zimmerman NE, GonzaloJimenez J, Grivet D (2017) Assessing vulnerability of two Mediterranean conifers to support genetic conservation management in the face of climate change. Diversity and distributions (In press) https://doi.org/10.1111/ddi.12544

Shanahan E, Irvine KM, Roberts DW, Litt A, Legg K, Daley R (2014) Status of whitebark pine in the Greater Yellowstone Ecosystem: A step-trend analysis comparing 2004-2007 to 2008-2011. U. S. Department of the Interior, National Park Service, Fort Collins, CO, USA, https://irma.nps.gov/App/Reference/Profile/2216554 Natural Resource Technical Report NPS/GRYN/NRTR- 2014/ 917

Shanahan EA (2015) Personal communication. Department of political science. Montana State University, Bozeman, MT, USA

Shepperd WD (2004) Techniques to restore aspen forests in the western U.S. Trans West Sect Wildl Soc 40:52-60

Stein BA, Glick P, Edelson N, Staudt A (2014) Climate-smart conservation: putting adaptation principles into practice. National Wildlife Federation, Washington, D. C

Stephenson NL, Millar CI (2012) Climate change: Wilderness' greatest challenge. Park Sci 28:34-38

Swanston CW, Janowiak MK (2012) Forest adaptation resources: climate change tools and approaches for land managers. U.S. Department of the Interior, Bureau of Land Management, Denver, CO, Gen. Tech. Rep. NRS-87

The Conservation Measures Partnership (2008) Open standards for the practice of conservation, Version 3.0, http://cmp-openstandards. org/wp-content/uploads/2014/03/CMP-OS-V3-0-Final.pdf. Viewed 7 March 2017

Thuiller W, Lavorel S, Araújo MB, Sykes MT, Prentice IC (2005) Climate change threats to plant diversity in Europe. Proc Natl Acad Sci USA 102:8245-8250. https://doi.org/10.1073/pnas. 0409902102
U.S. Fish and Wildlife Service (2011) Listing of whitebark pine ruling at: http://www.fws.gov/mountain-prairie/species/plants/whiteba rkpine

U.S. Geological Survey (USGS) (2006) Federal lands of the United States. U.S. Geological Survey, Reston, VA, https://catalog.data. gov/harvest/object/6bec8d3c-fff4-4037-8028-9b1d7ff64814/ $\mathrm{html} /$ original

van de Gevel SL, Larson ER, Grissino-Meyer HD (2017) Separating trends in whitebark pine radial growth related to climate and mountain pine beetle outbreaks in the Northern Rocky Mountains, USA. Forests 8 https://doi.org/10.3390/f8060195

Walters C (1986) Adaptive management of renewable resources. Macmillan, New York, NY, USA

Warwell MV, Rehfeldt GE, Crookston NL (2007) Modeling contemporary climate profiles of whitebark pine (Pinus albicaulis) and predicting responses to global warming. Paper presented at the Proceedings of the Conference on Whitebark Pine: A Pacific Coast Perspective Forest Service R6-NR-FHP-2007-01, U.S. Department of Agriculture, Ashland, OR, USA. 26-27 August 2006

Weaver T (1994) Vegetation distribution and production in Rocky Mountain climates- with emphasis on whitebark pine. In: Schmidt WC, Holtmeier FK (eds) Proceedings International workshop on subalpine stone pines and their environments: the status of our knowledge. US Department of Agriculture Forest Service, Ogden, UT, pp. 142-152. General Technical Report INT-GTR309

West JM et al. (2009) US natural resources and climate change: Concepts and approaches for management adaptation. Environ Manag 44:1001-1021. https://doi.org/10.1007/s00267-009-9345-1

Westerling AL, Hidalgo HG, Cayan DR, Swetnam TW (2006) Warming and earlier spring increase western U.S. forest wildfire activity. Science 313:940-943

Willows RI, Connell RK (eds) (2003) Climate adaptation: risk, uncertainty and decision-making. United Kingdom Climate Impacts Programme technical report. United Kingdom Climate Impacts Program, Oxford, U.K

Worrall JJ, Rehfeldt GE, Hamman A, Hogg EH, Marchetti SB, Michaelian M, Gray LK (2013) Recent declines of Populus tremuloides in North America linked to climate. For Ecol Manag 299:35-51. https://doi.org/10.1016/j.foreco.2012.12.033 